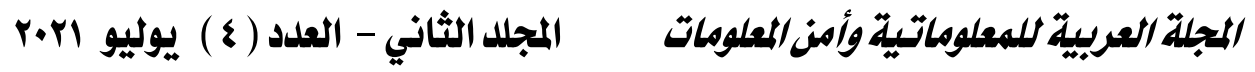

\title{
إدارة المعرفة والإدارة بالمعرفة
}

Knowledge Management and Management by knowledge

\author{
إعلاد \\ أ. د/ مدحت محمد أبو النصعر \\ Prof. Dr. Medhat Mohamed Abo El Nasr \\ رئيس قسم المجالات كلية الخدمة الاجتماعية بجامعة حلوان ( سابقا )
}

Doi: 10.21608/jinfo.2021.183902

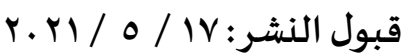

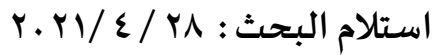

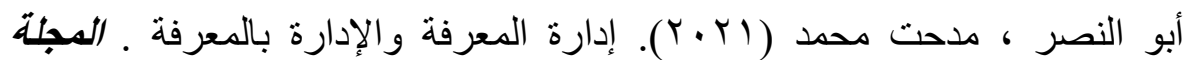

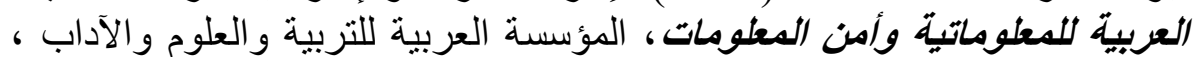

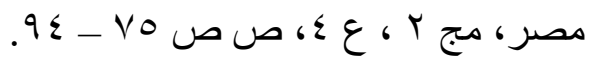




\section{إدارة المعرفة والإدارة بالمعرفة}

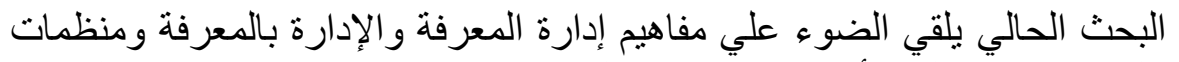

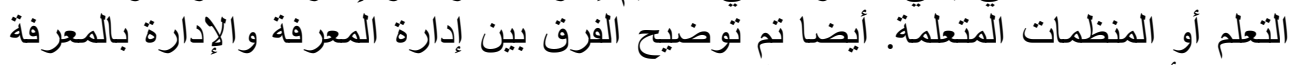
وتحديد أهمية ووظائف ومؤشرات كل منهما. وكنوع من التمهيد للمكونات السابق الإشارة

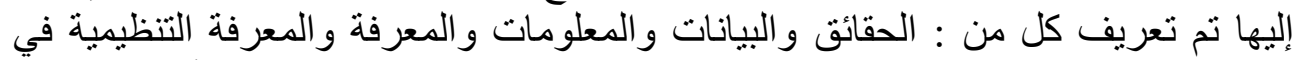
بداية البحث. وفي نهاية البحث تم تقديم مجموعة من التوصيات التي يمكن أن تساهم في

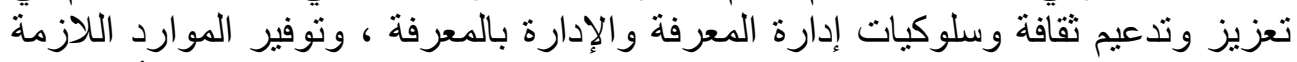

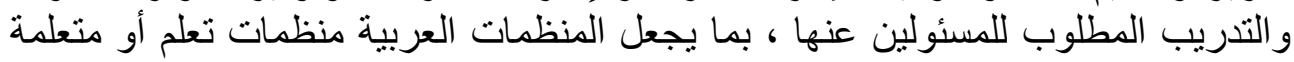
تتصف بالكفاءة و الفاعلية و الجودة.

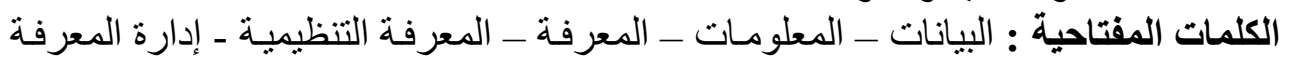

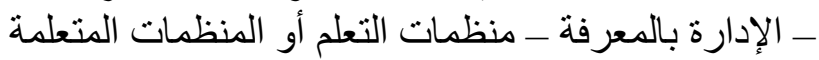

\section{Abstract:}

The current research shed light on the concepts of knowledge management, management by knowledge, and learning organizations. Also, the difference between knowledge management and management by knowledge was clarified and the importance, functions and indicators of each were identified.As a kind of preparatory step, the following concepts: facts, data, information, knowledge and organizational knowledge were defined at the beginning of the research.At the end of the research, a set of recommendations were presented that could contribute to strengthening and supporting the culture and behaviors of knowledge management and management by knowledge, and providing the necessary resources and required training for those responsible for it, so that Arab organizations become learning organizations characterized by efficiency, effectiveness and quality.

Keywords: Data - information - knowledge - Organizational knowledge - knowledge management - Management by knowledge learning organizations 


\section{المجلد الثاني - العدد ( ₹ ) يوليو ابr}

\section{المجلة العربية للمعلوماتية وأمن المعلومات}

مقدمة:

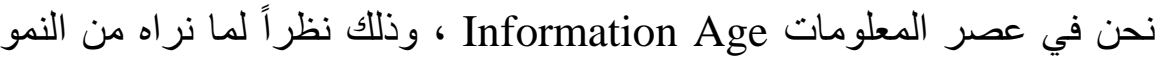

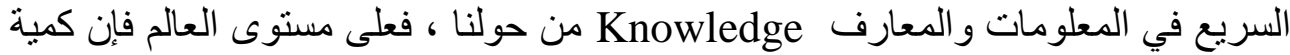

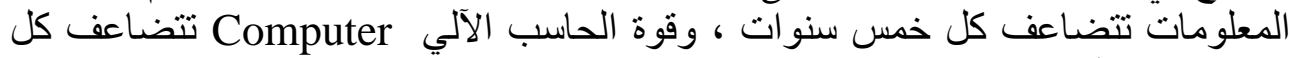
سنتين على الأقل .

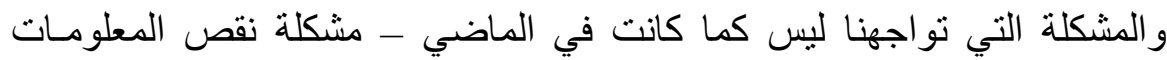

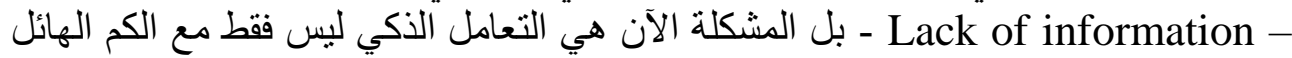

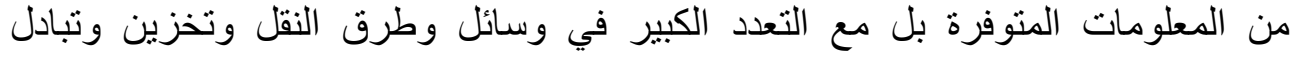
المعلومات . هن معات

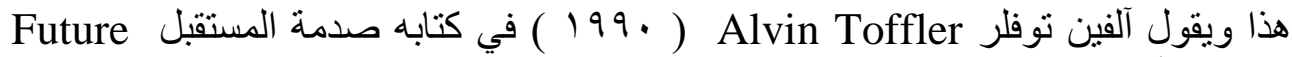
Shock

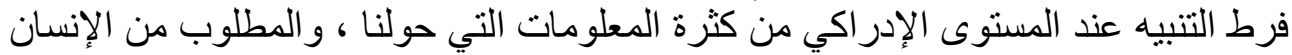

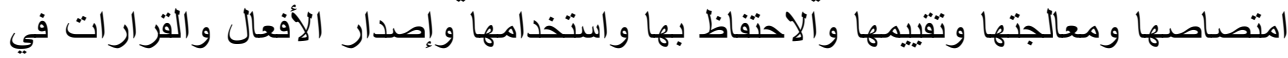

ضوئها.

أيضا نحن نعيش ثورة المعلومات Information Revolution الذي يقوم فئو فيه الحاسب

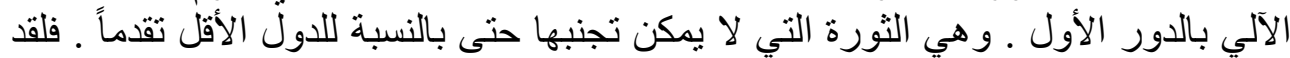

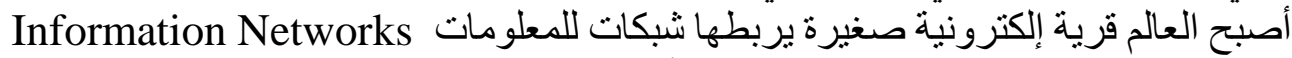

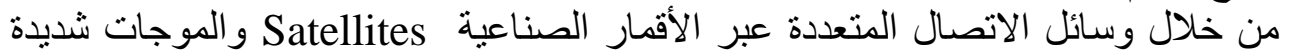

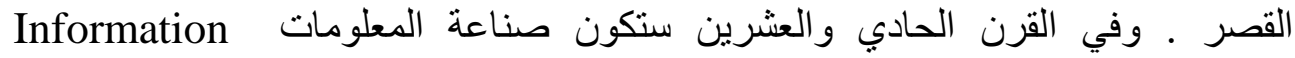

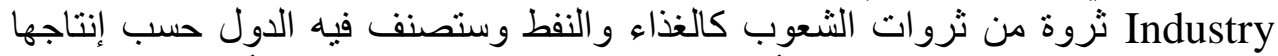

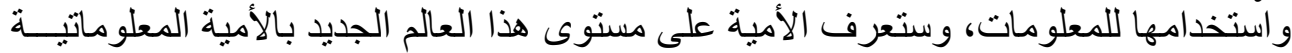

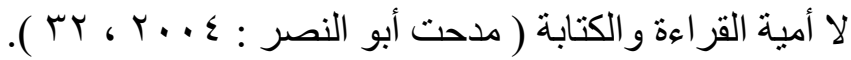

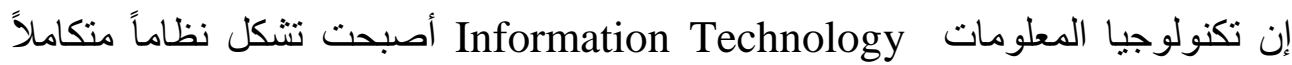

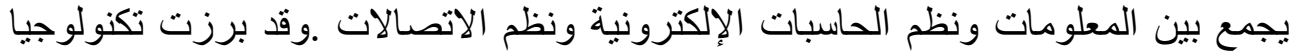

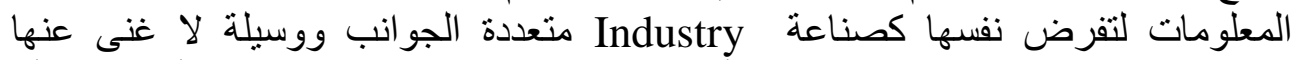

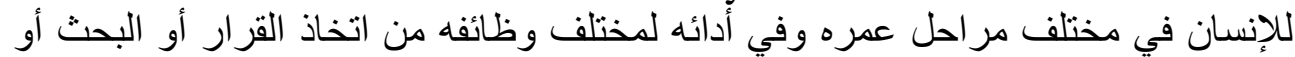

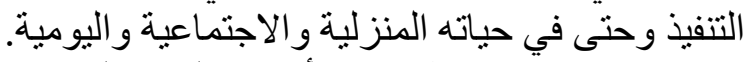

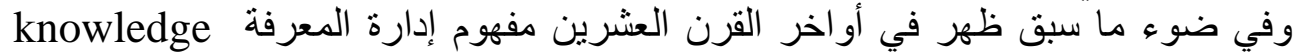
Management

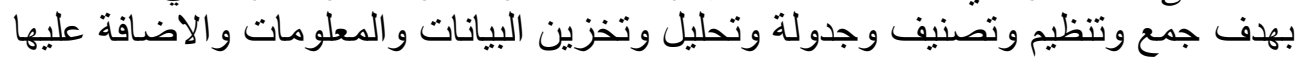
و استرجاعها وتو فير ها بأثكال مناسبة ومفهومة ونة للعاملين في المنظمات للاستفادة منها. 
فإدارة المعرفة هي تخصص مهني و علمي لأخصائي ومهندسي الحاسبات والمعلومات

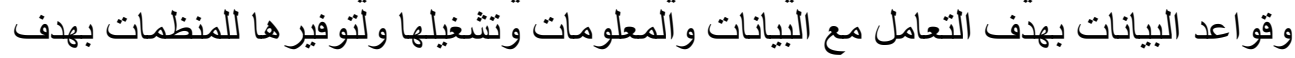

الاستفادة منها.

أما بالنسبة للإدارة بالمعرفة Management by Knowledge فلقد ساهم عدد من علماء

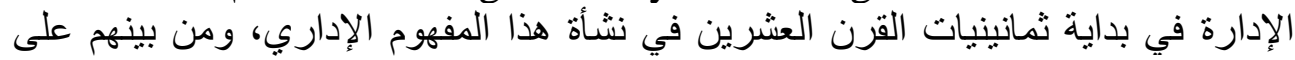

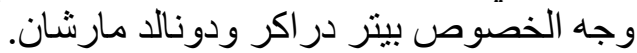

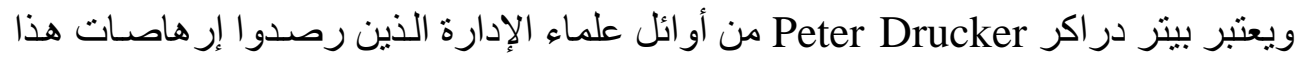

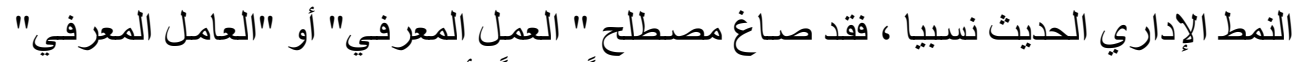
"Knowledge Worker

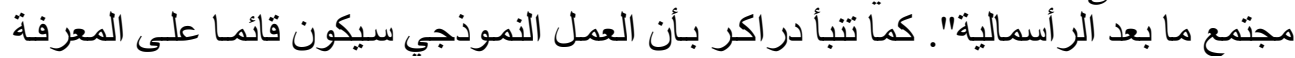

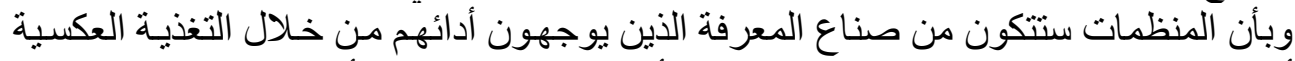

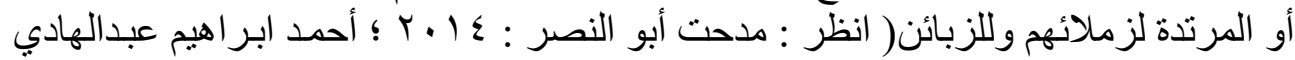
(r...人 : و الإدارة بالمعرفة هي مسئولية المدر اء و العاملين و الذين يجب أنان وان بستفيدون ويسترشدون

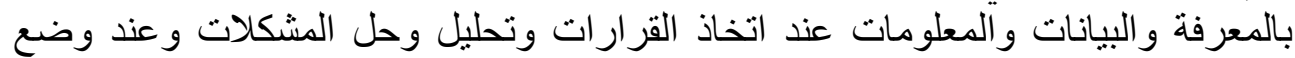

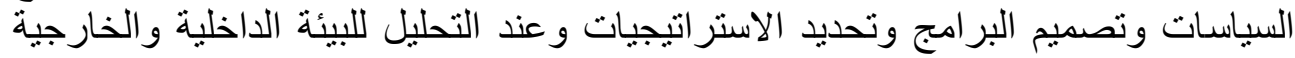
للمنظمة...

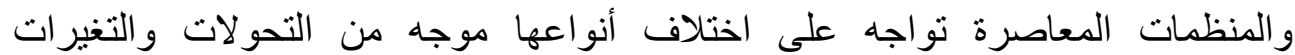
المنسارعة التي تجتاح عالم اليوم وفي مقدمتها ثورة التورة الحاسبات الآلية وثورة التورة الاتصالات و والثورة المعلومناتية.

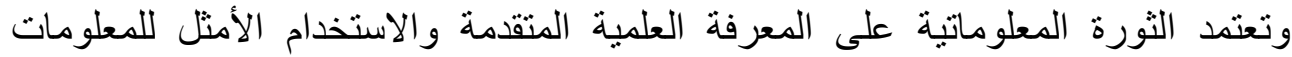

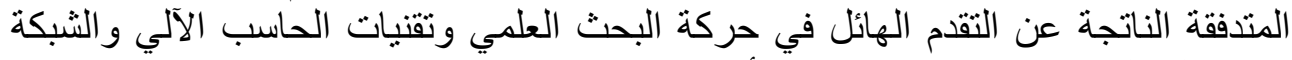

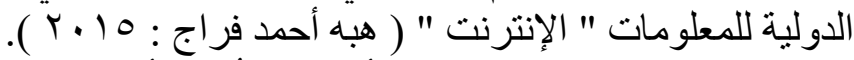

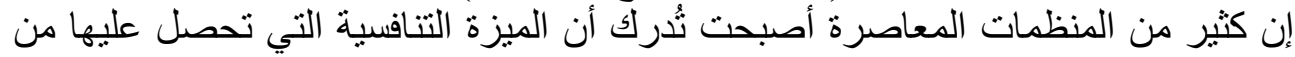

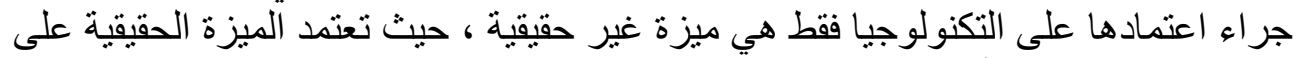

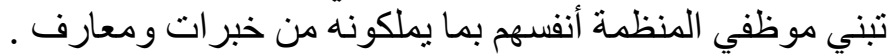

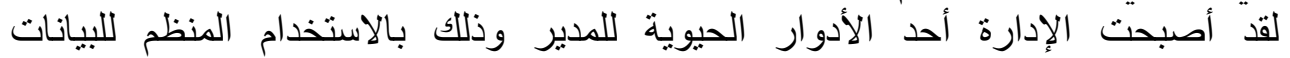

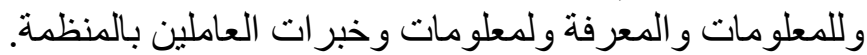

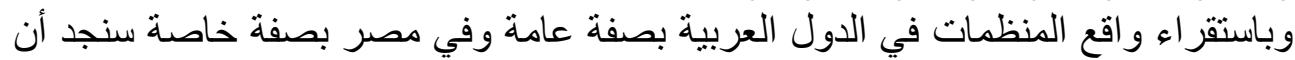

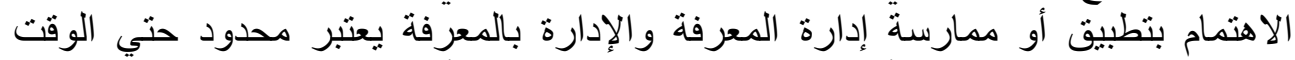

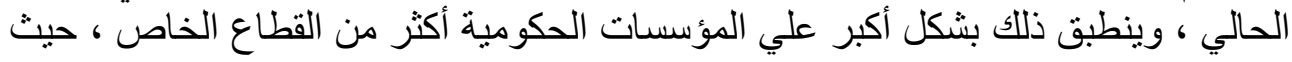




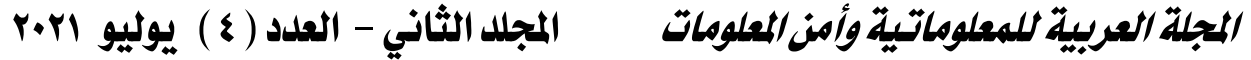

أثنتت بعض البحوث والدراسات السابقة إلي قلة اهتمام معظم المنظمات العربية بثقافة

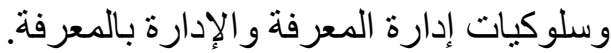

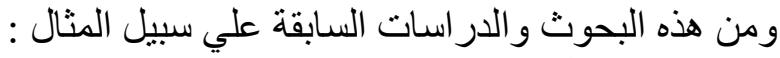

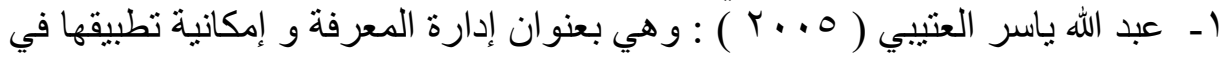

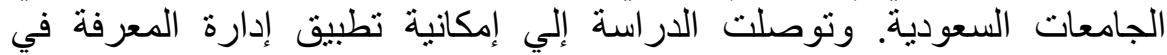

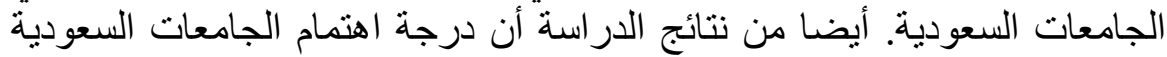

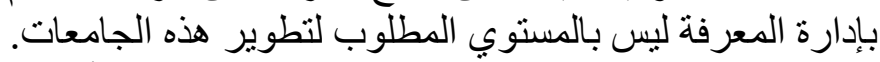

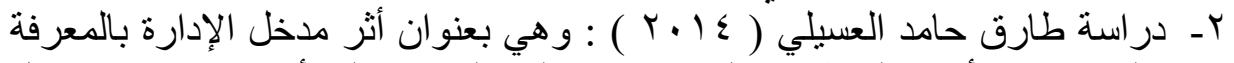

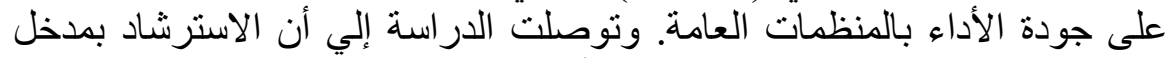

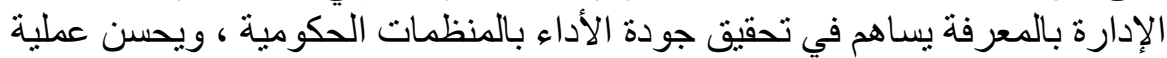

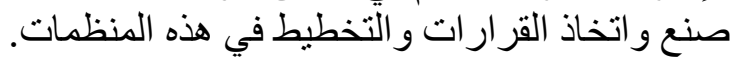

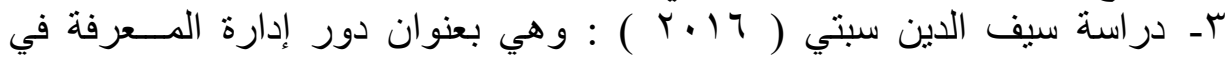

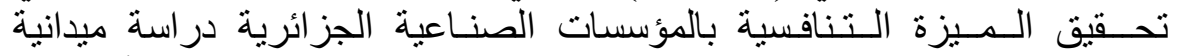

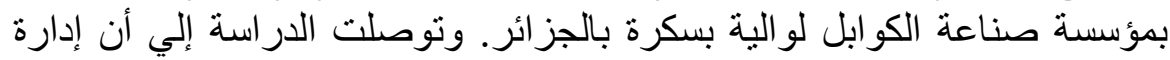

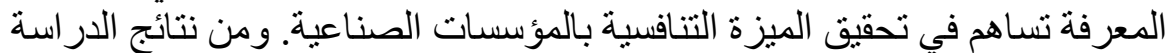

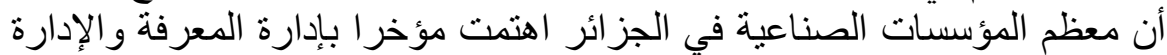
بالمعرفة.

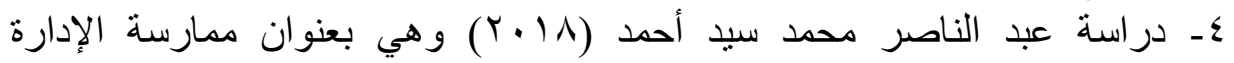

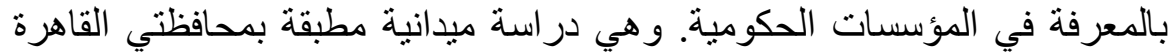

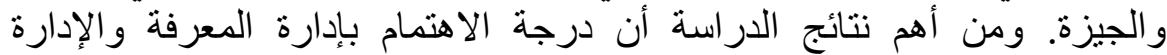

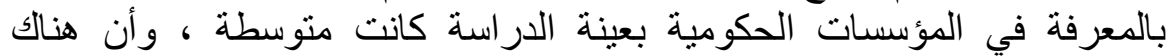

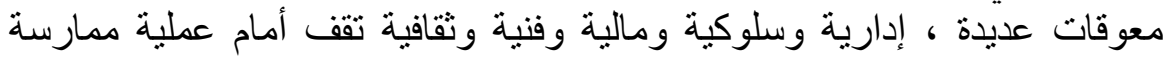

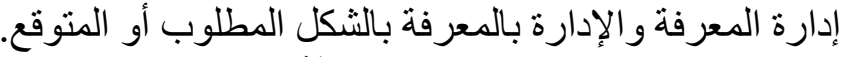

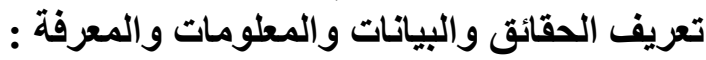

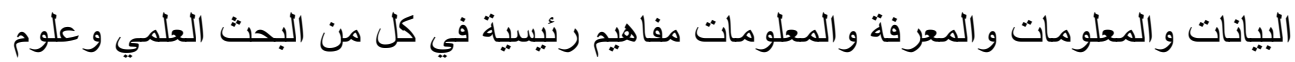

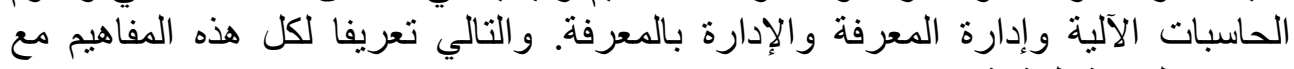
توضيح العلاقة الوثيقة فيما بينهم.

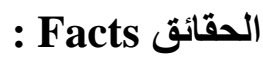

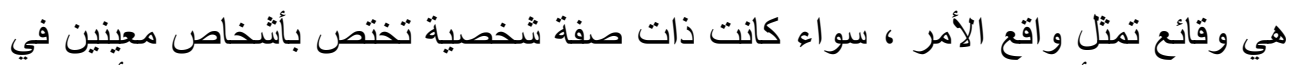

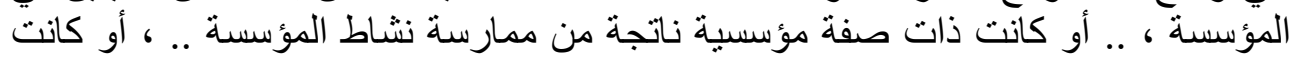

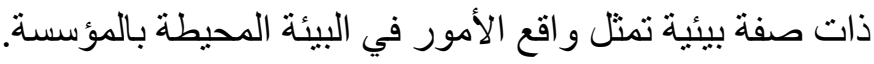

: Data البيانات 
هي مجموعة من الحقائق الأولية أو الخام Raw Facts التي يتم تسجيلها بواسطة رموز Symbols

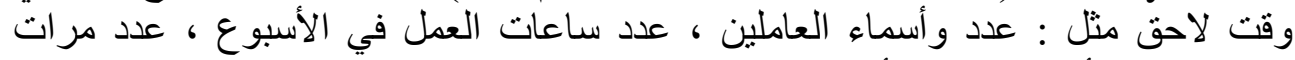

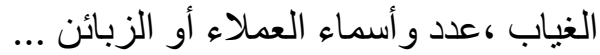

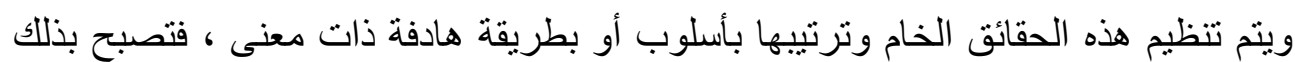

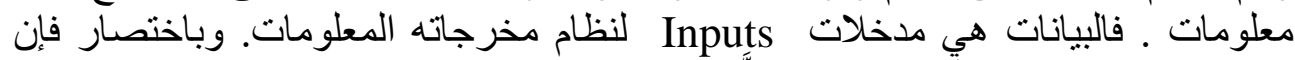

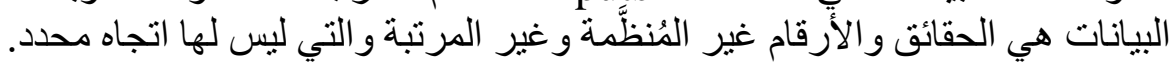

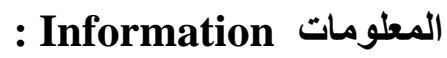

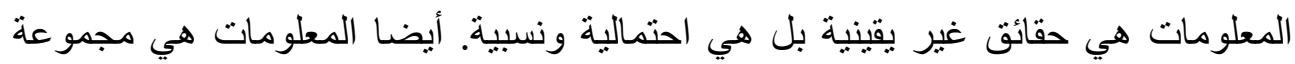

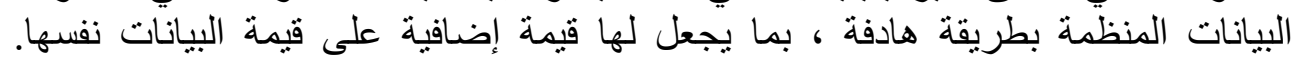

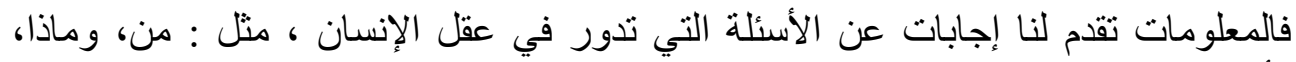

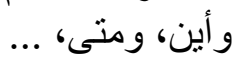

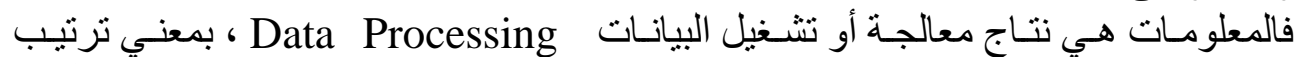

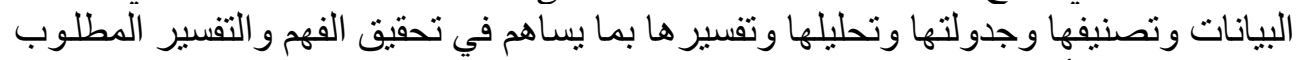
لموضوع معين أو لتحقيق هدف وندان محدد.

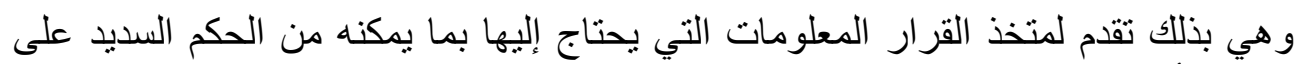

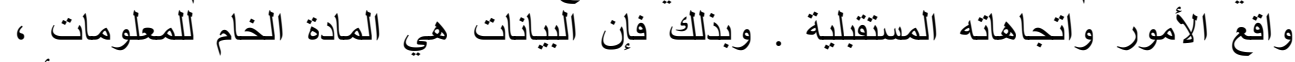

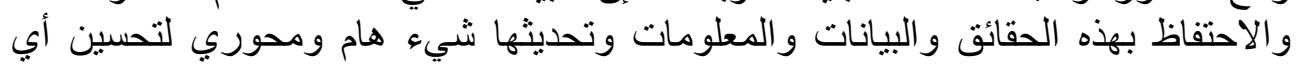
عمل.

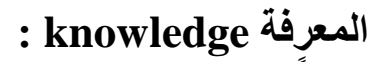

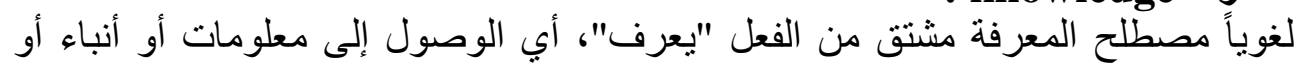

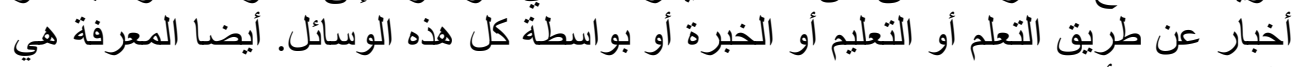
كل معروف أو مفهوم ( Oxford : Wikipedia Encyclopedia :

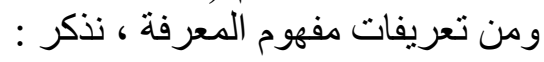

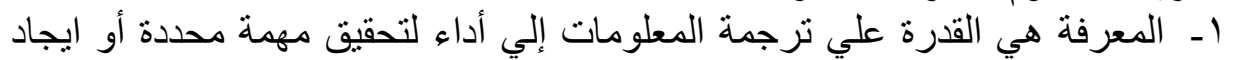

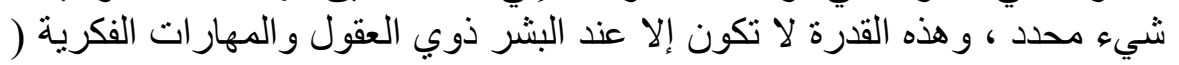

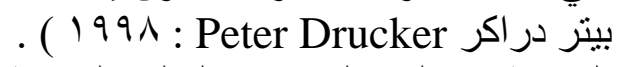

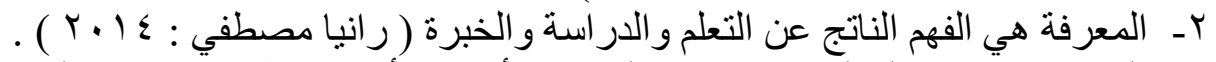

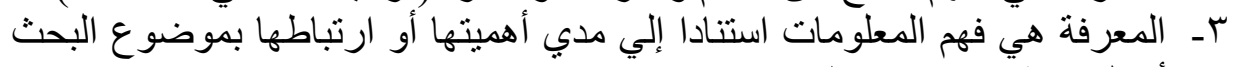

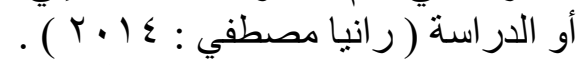

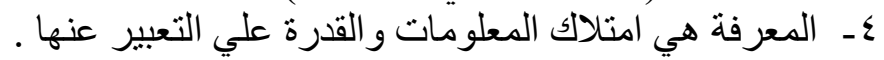




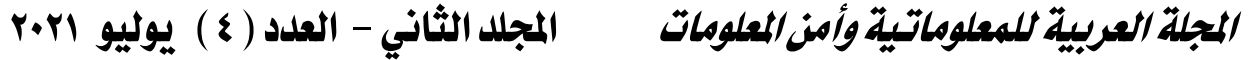

$$
\text { 0ـ - المعرفة هي كل ماهو معروف أو مفهوم. }
$$

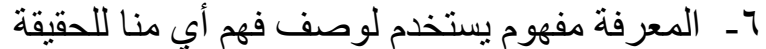

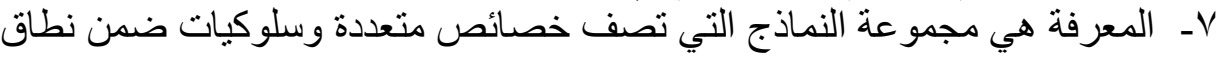

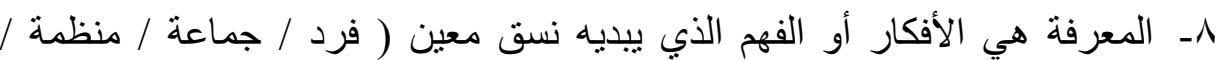

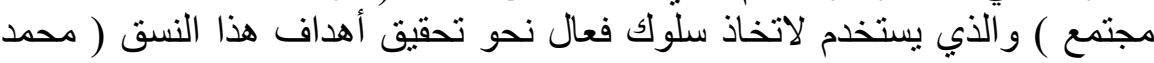

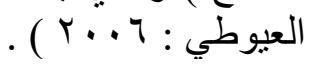

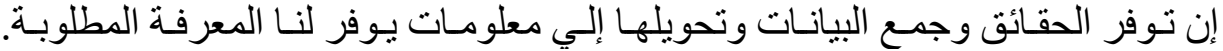

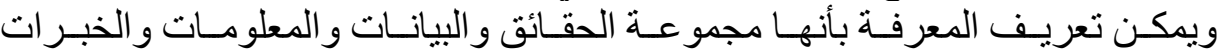

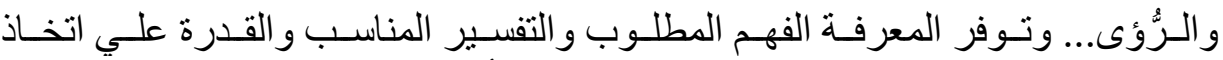

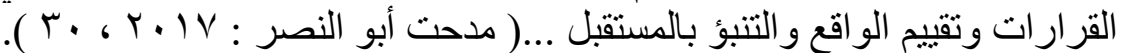

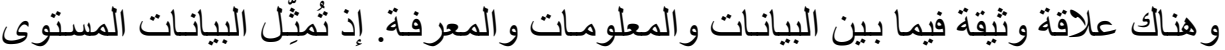

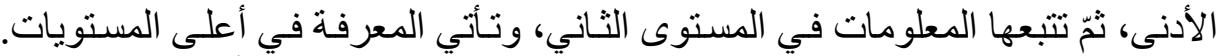

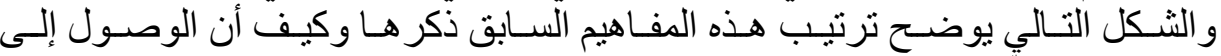

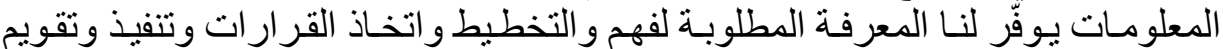

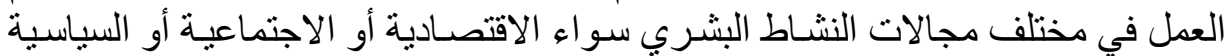
أو العسكرية ... ، و إجراء البحوث الأساسية و التطبيقية في مجالي الخدمات و الإنتاج .

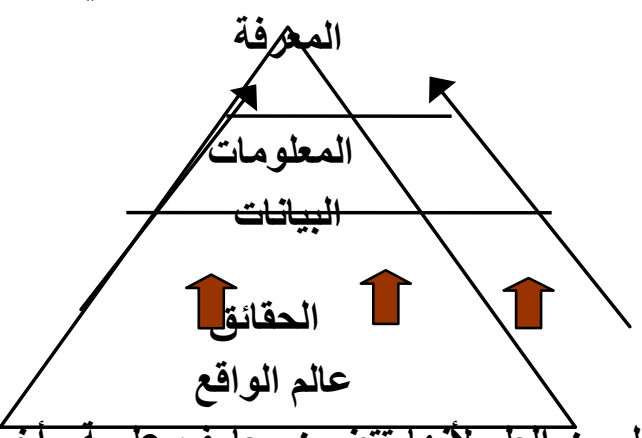

والمعرفة أوسع وأشمل من العلم لأنها تلضمن معارف علميّه واخري معارف غير علمية.

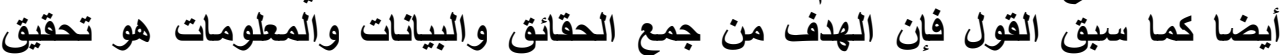

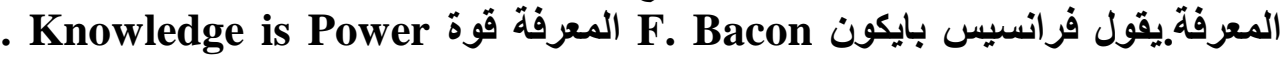
A little learning or knowledge is a dangerous : شالمثل الإنجليزي يقول thing ـ بمعنى أن "العلم القليل ( أو المعرفة القلّيلة ) شئئ خطر " . وبقابل هذا المثل في العربية "نصف العلم أخطر من الجهل". أي أن العلم الناقص قد يضل المرء

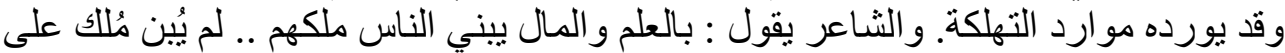




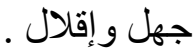

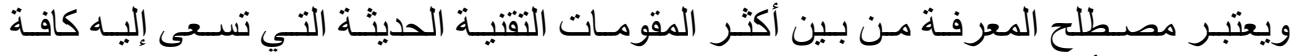

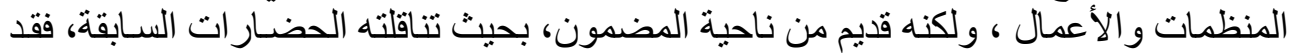

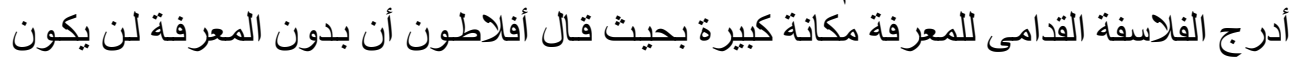

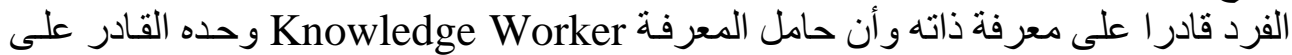

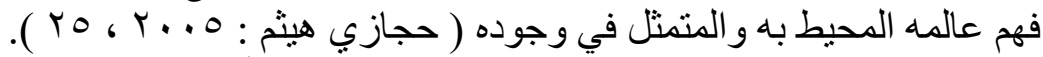

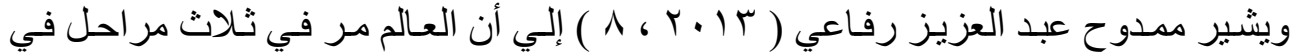

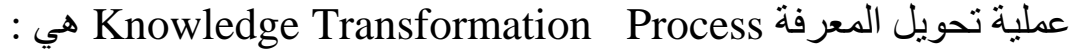

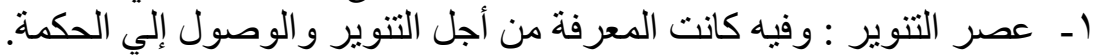

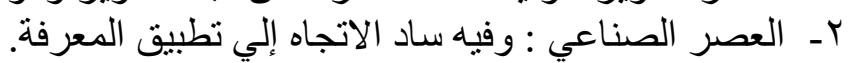

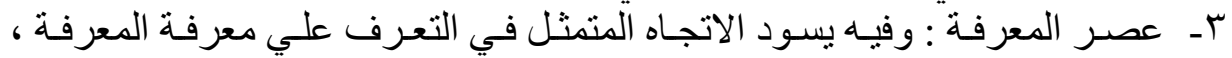

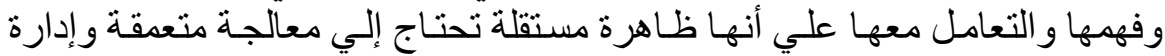

رشيدة.

خصائص المعرفة : مندة.

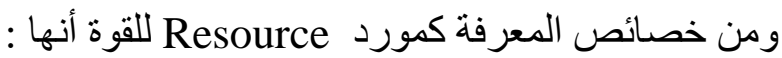

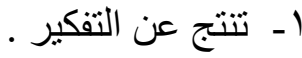

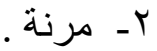

r- ـ لا تنقص كميتها باستخدامها (على عكس أثنكال القوة الأخرى مثل : الثروة و العنف . ( ... ـ - - جماعية استخدامها .

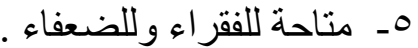

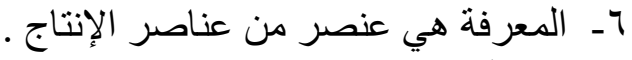

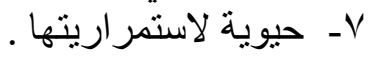

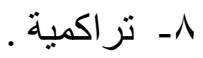

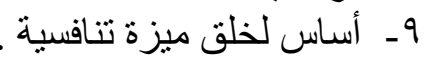

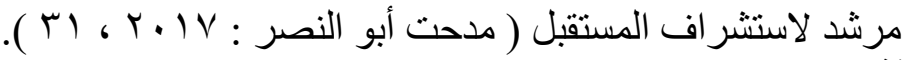
-1 . دورة تطور المعرفة : مونة

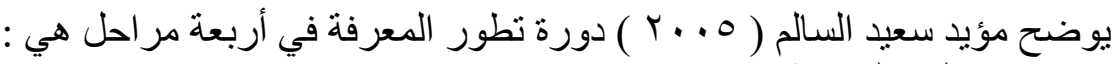
Knowledge Creation Knowledge Distribution Knowledge Sharing 1 - 1 - تخليق المعرفة

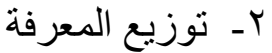

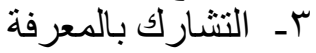
Knowledge Capture \& Codification

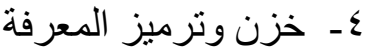




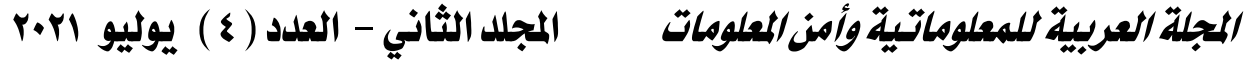

وبشيء من التفصيل يمكن تحديد ست مر احل في دورة تطور المعرفة ، هي كالتالي :

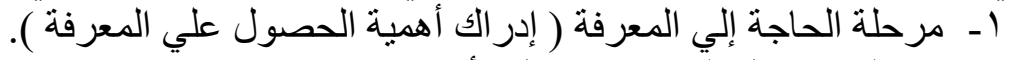

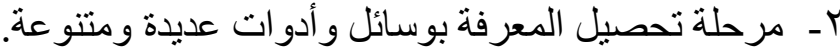

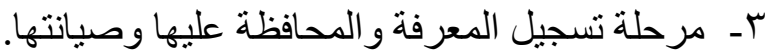

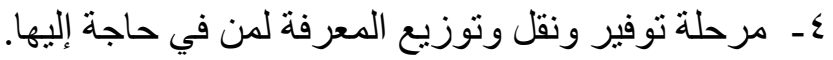

هـ ـ مرحلة تطبيق المعرفة و الاستفادة منها.

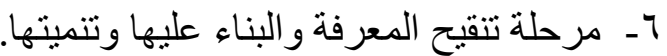

\section{المعرفة التنظيمية Organizational Knowledge:}

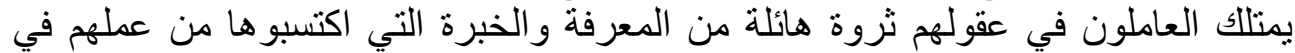

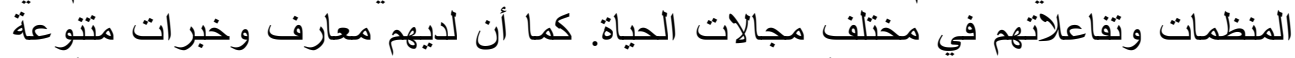

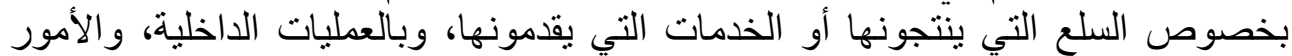

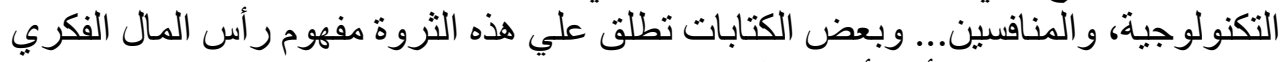
Intellectual capital

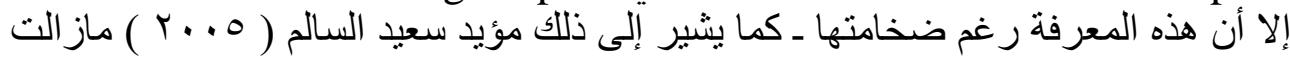

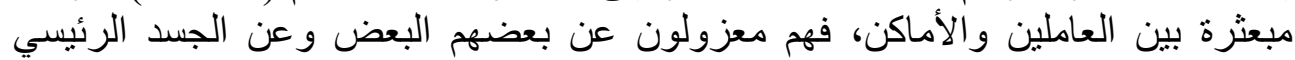

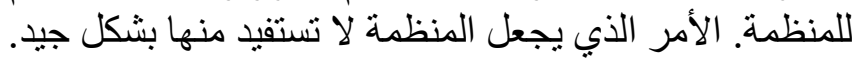

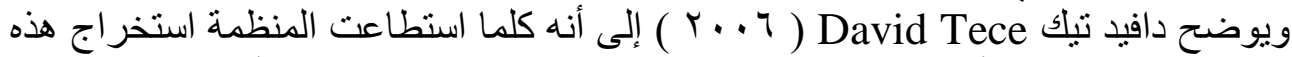

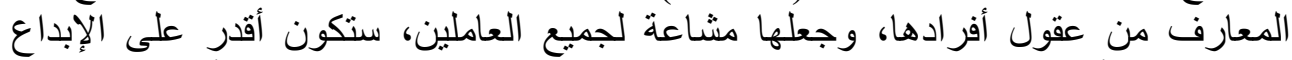

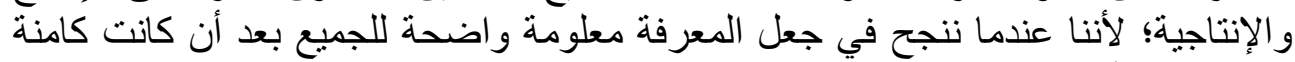

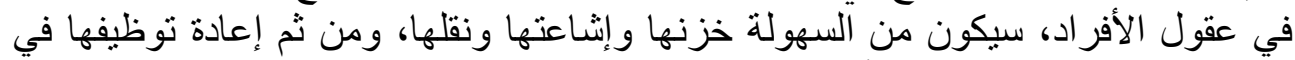

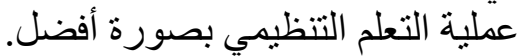

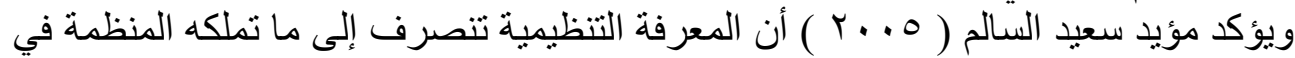

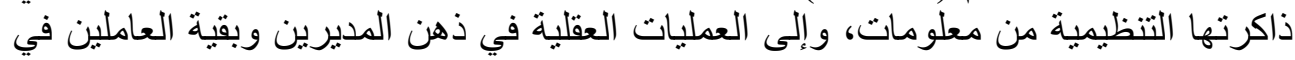

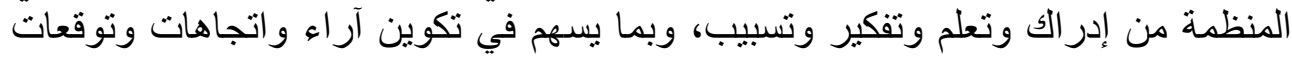

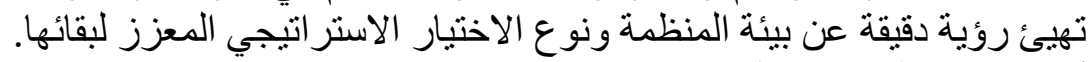
أنواع المعرفة التنظيمية : توفئة

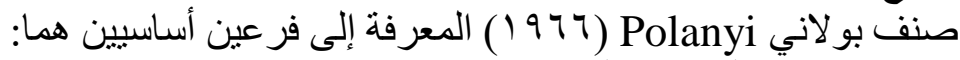

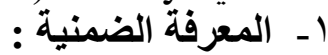

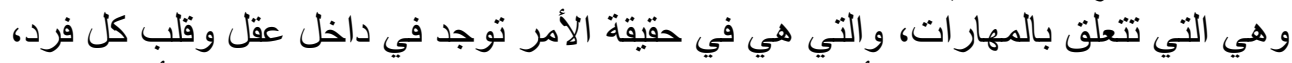

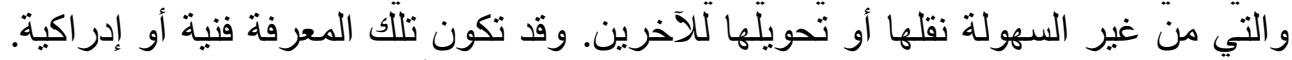

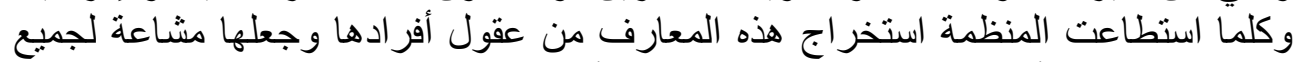
العاملين، ستكون أقدر على الإبداع والإنتاجية، لأننا عندما ننجح في جعل المعار المعرفة معلومة المهاع 
وو اضحة للجميع بعد أن كانت كامنة في عقول الأفراد، سيكون من السهولة خزنهاو إنثاعتها

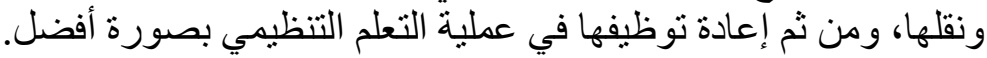

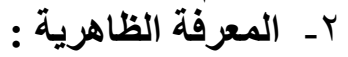

و هي التي تتعلق بالمعلومات الموفية المودودة في أرشيف المنظمة ومنها (الكتيبات المتعلقة

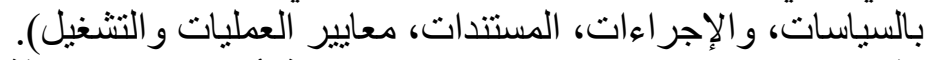

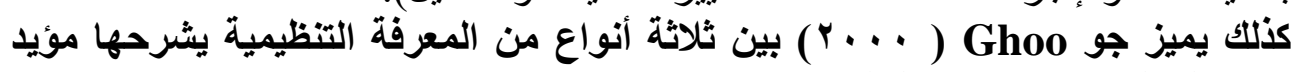

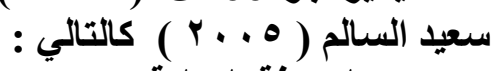

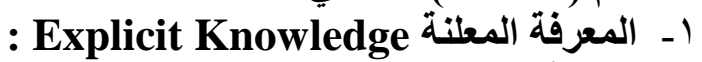

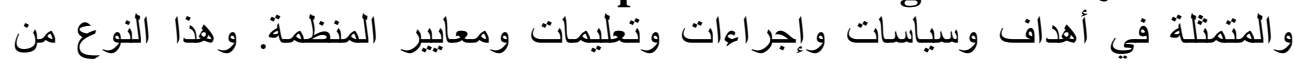

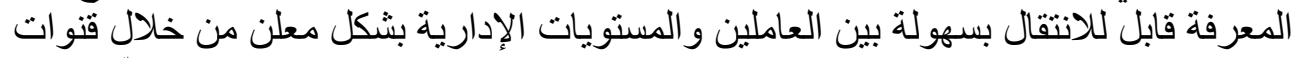

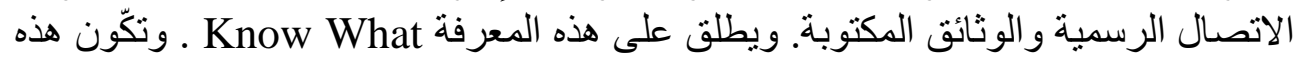

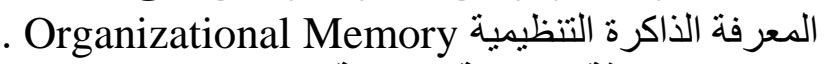

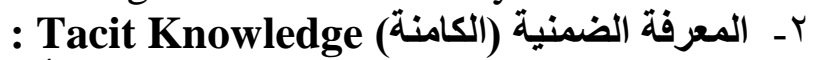

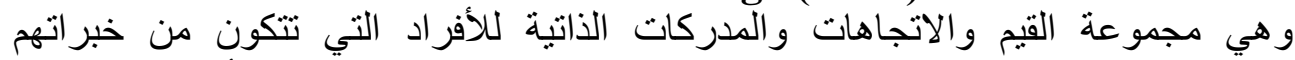

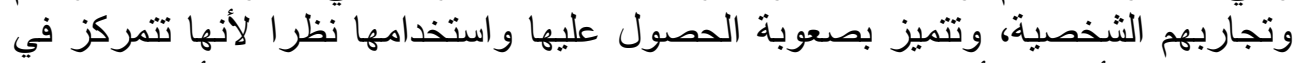

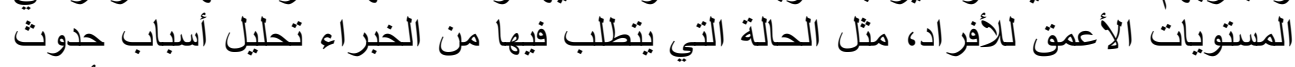

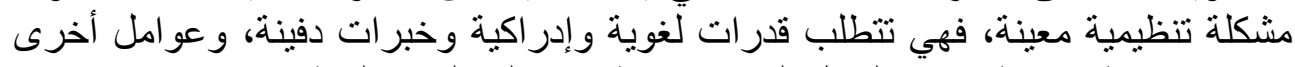

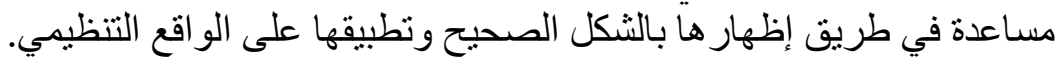

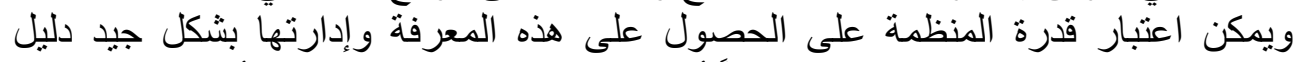

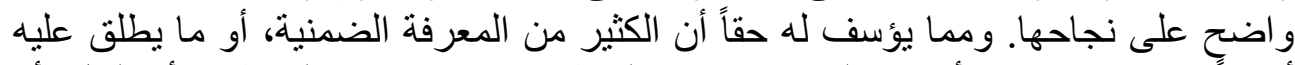

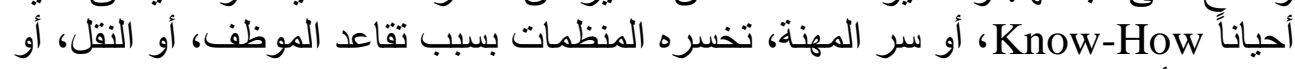
الاندماج أو تقليص حجم النشاط.

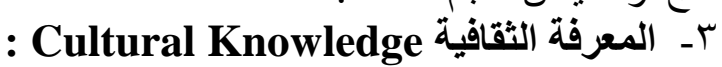

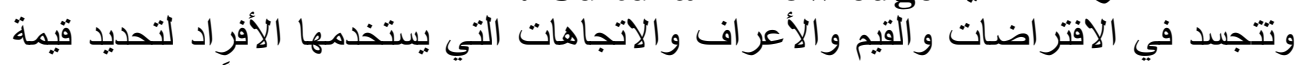

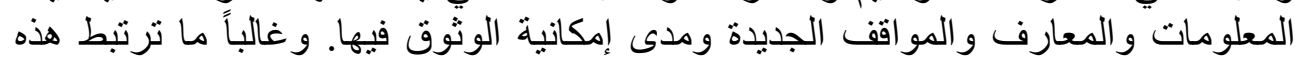

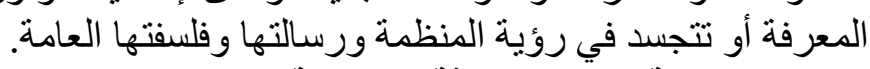

مرتكزات عملية تكوين المعرفة التئة التظيمية:

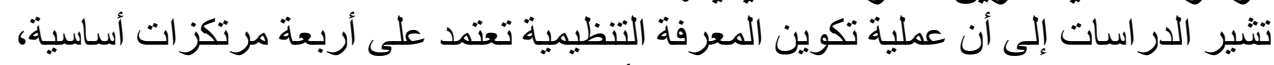

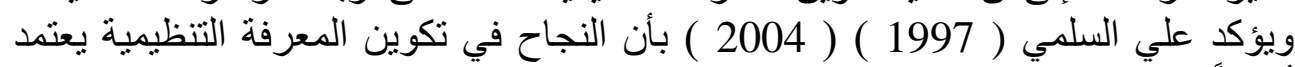

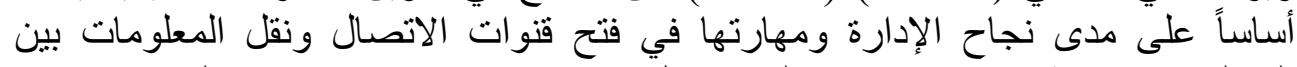

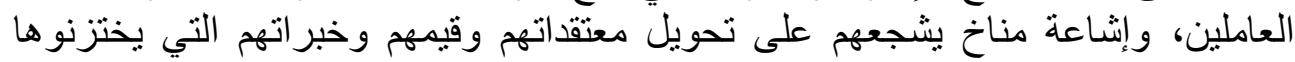
بداخلهم إلى كلمات وقضايا مفيدة معلنة يمكن تداولها و انتشار ها في المنظمة، حتى يمكن لها 


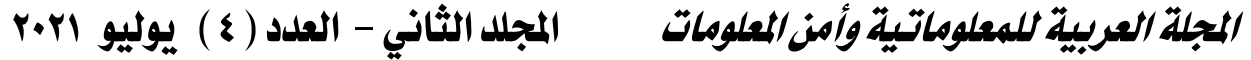

أن تجد طريقها للاندماج في عمليات وخطط ومنتجات ونظم وخدمات المنظمة. ونون ومن هنا

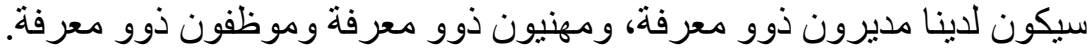

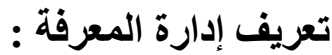
هناك تعريفات عديدة لمفهوم إدارة المعرفة : المعة ، منها :

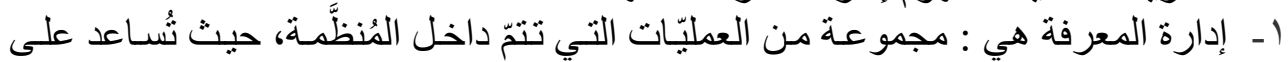

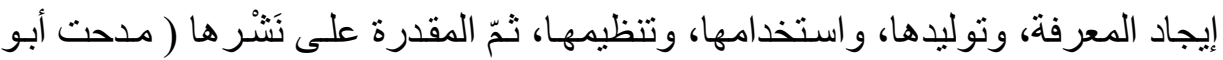

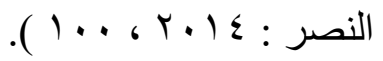

r- إدارة المعرفة هي : التقنيات و الأدوات و والموارد البشرية المستخدمة لجمع و إدارة ونشر مـ

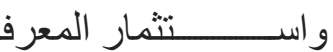

https://ar.wikipedia.org/wiki/\%D8\%A5\%D8\%AF\%D8\%A7

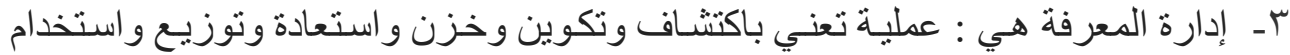

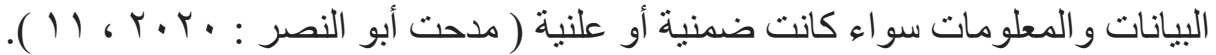

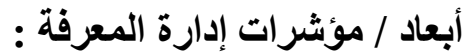
يمكن تحديد أهم أبعاد أو مؤشرات المعرة إن إدارة المعرفة في التالي :

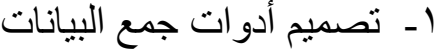

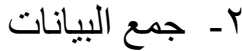

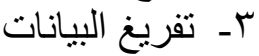
ـ ـ ـ تصنيف البيانات 0ـ - - جدولة البيانات 7- ت ت تحليل البيانات 人

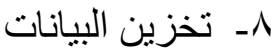

9 ـ ـ المحافظة علي البيانات من السرقة و التلف و الافساد و التحوير و التضليل

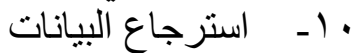

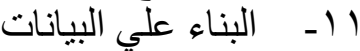

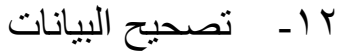

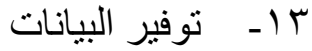
تعريف الإدارة بالمعرفة: توفيرة هنالك تعريفات عديدة لمفهوم الإدارة بالمعرفة ، بلمة ، منها : 


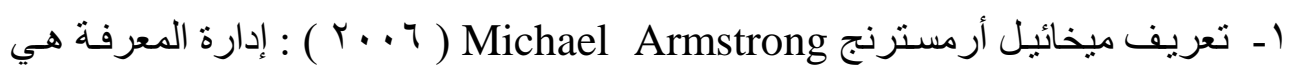

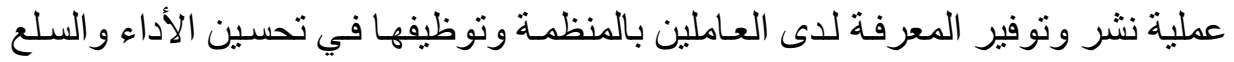

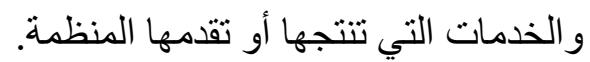

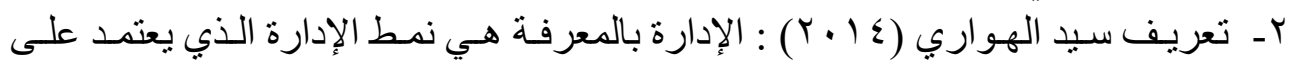

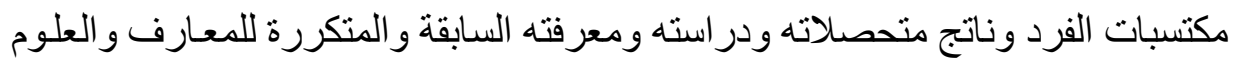

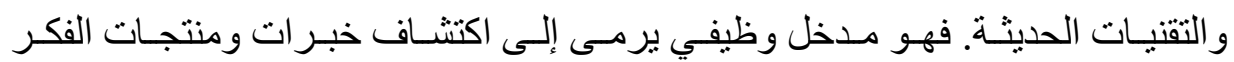

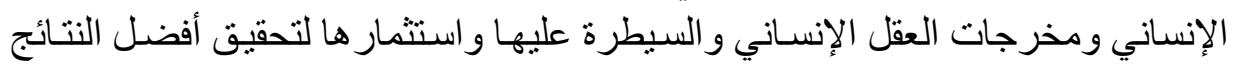
للمؤسسات و المنظمات المعاصرة.

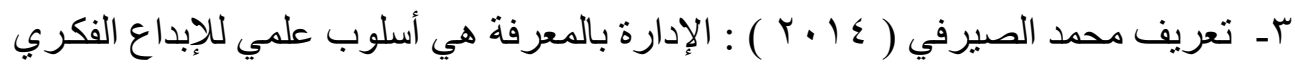

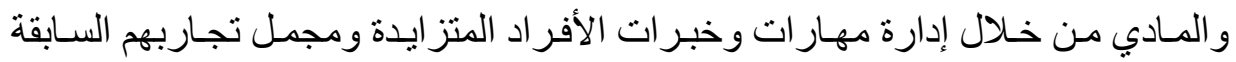

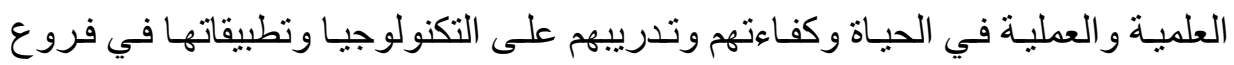
العلوم المختلفة ومزج القديم بالمستحدثات و المستجدات المحيطة بنا.

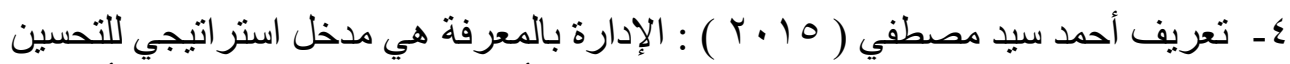

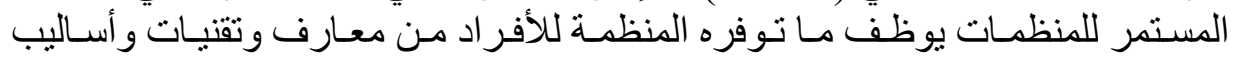

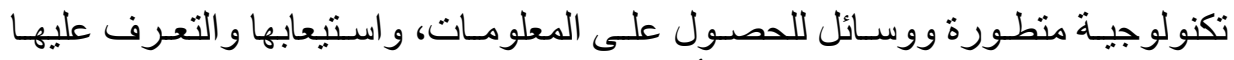

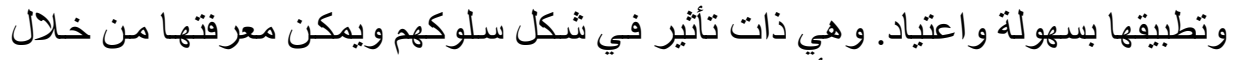

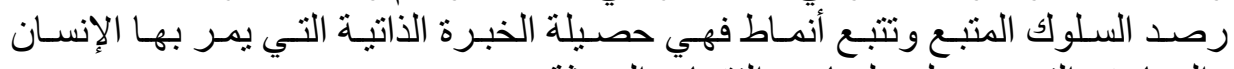

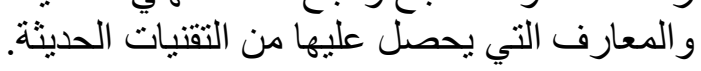

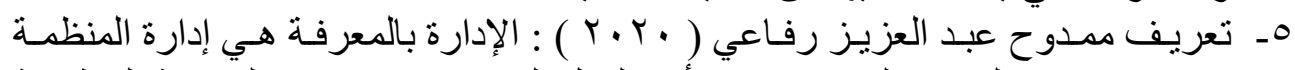

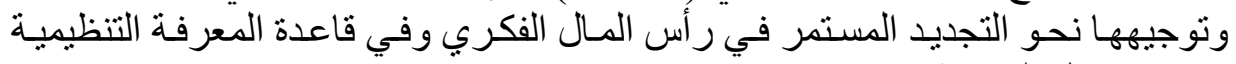
ونشر وتبادل المعرفة وتنو التميتها.

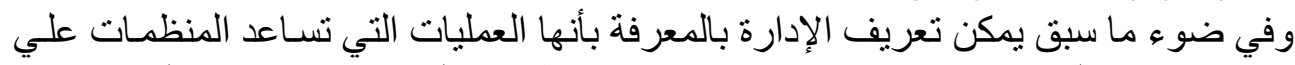

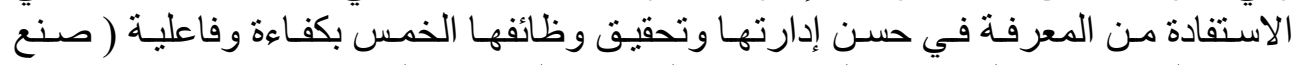

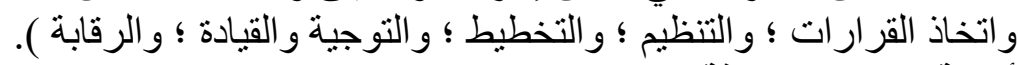

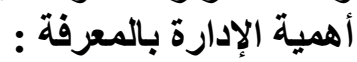

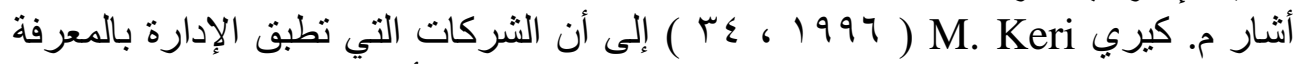

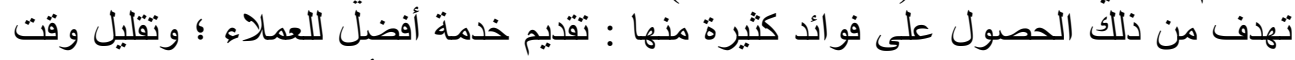

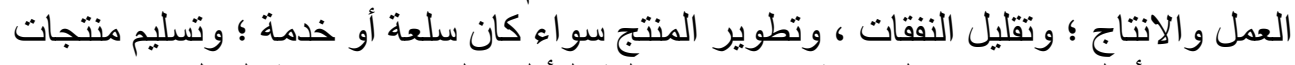

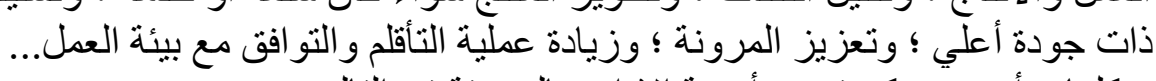

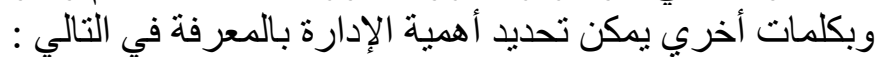

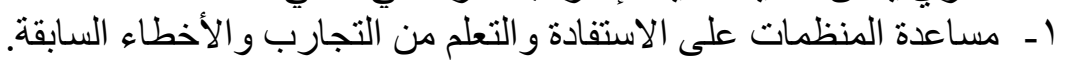




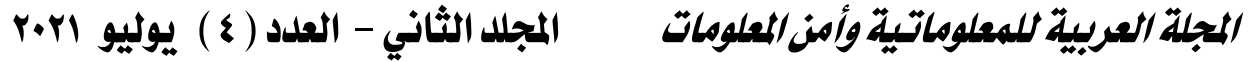

r- المساهمة في تطوير قدرة المنظمة على الابداع و الابتكار والاختر اع.

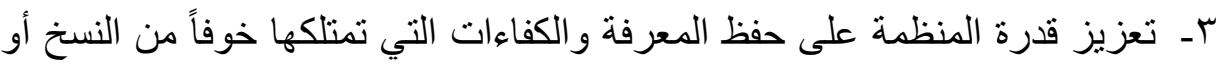

$$
\text { الضبياع. }
$$

ـ ـ تعزيز إمكانية المنظمة على استبدال المعرفة القديمة. هـ ـ تطوير الكفاءات و المهار ات الصحيحة على المنى المدى الطويل.

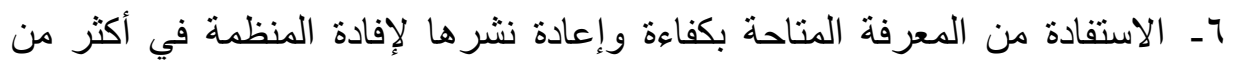

$$
\text { مجال وفي أكثر من وظيفة. }
$$

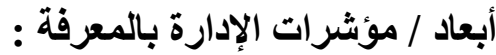

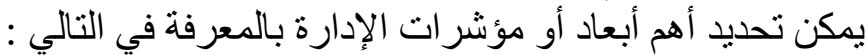

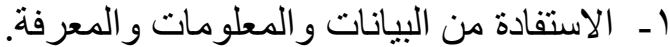

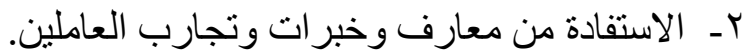

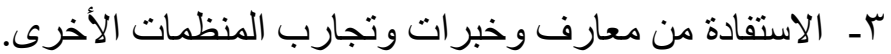

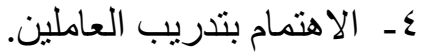
0ـ ـ الاهتمام بالتنمية المهنية المستمرة المامين. للعاملين.

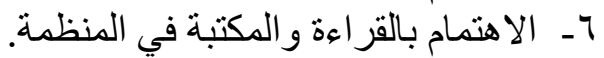

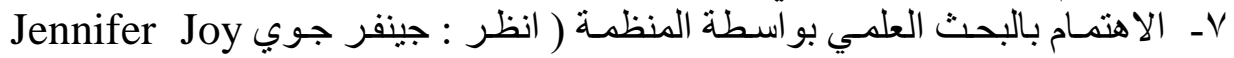

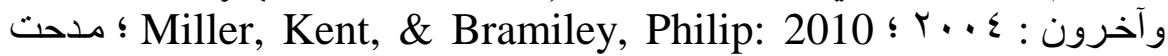

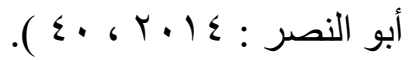

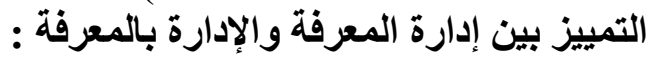

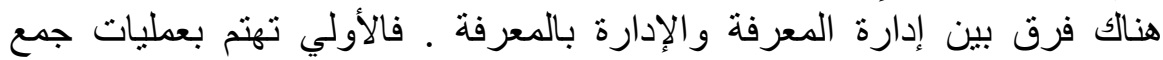

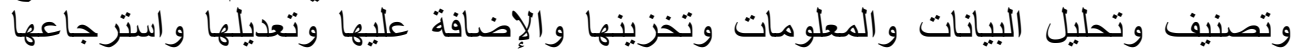

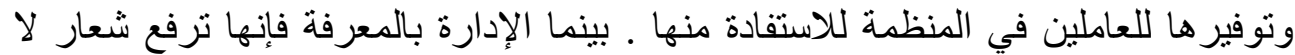

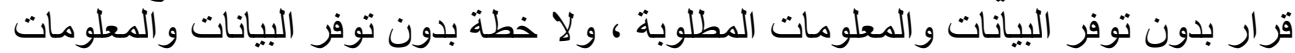

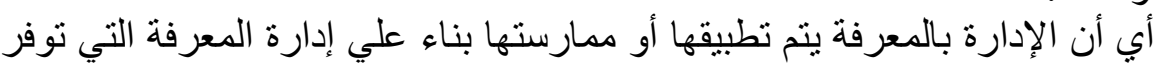

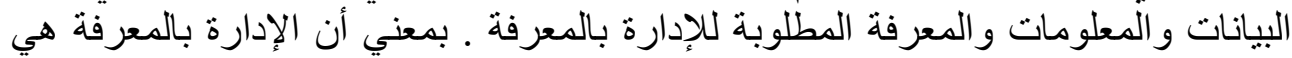

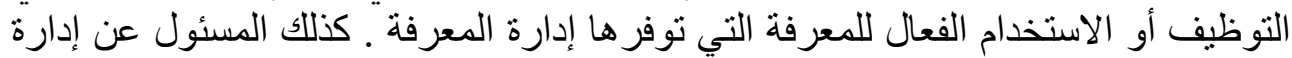

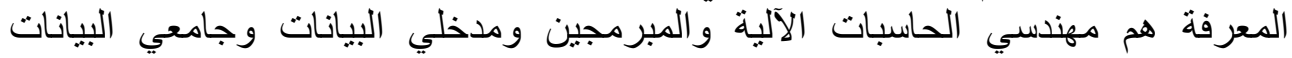

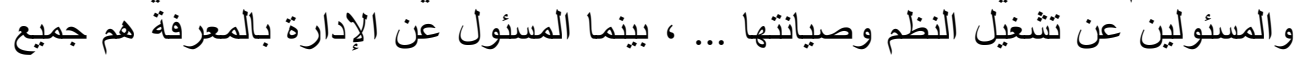

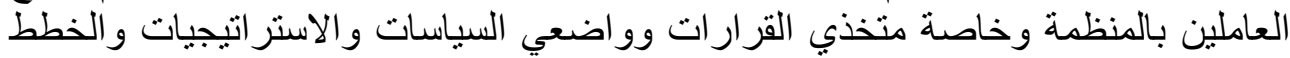

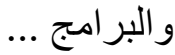


وتزداد كفاءة نظم إدارة المعرفة بالحصول علي حاسبات آلية متقدمة وتوفير برامة بامج حاسوبية

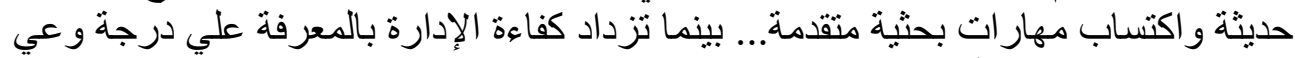

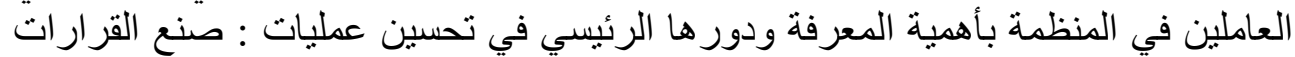

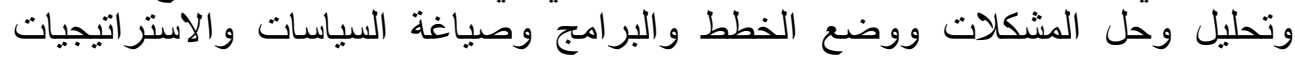

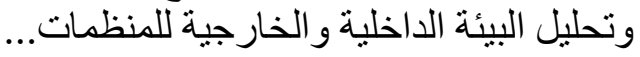
منظمات التعلم أو المتعلمة :

يري بيتر سينج أن Peter Senge (1990) أن منظمات التعلم أو المنظمات المتعلمة Learning Organizations

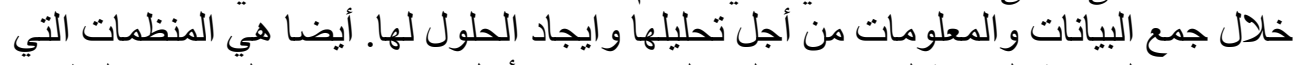

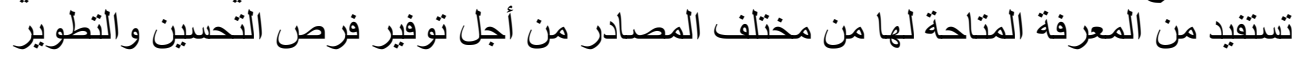

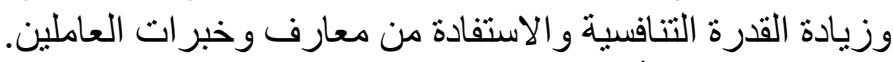

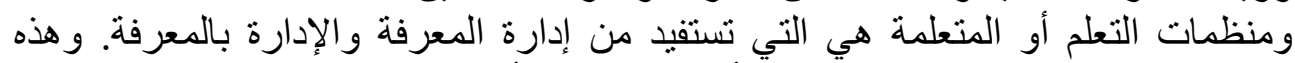

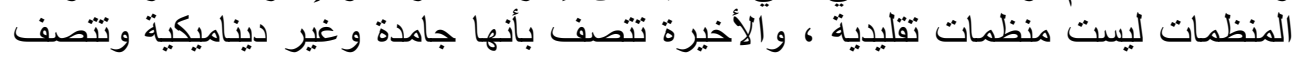

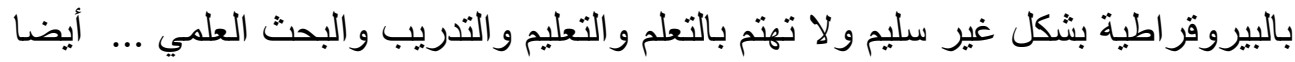

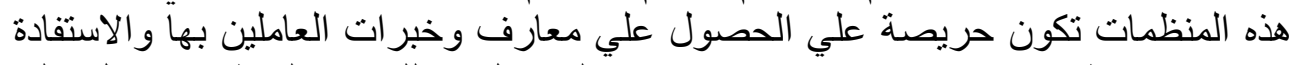

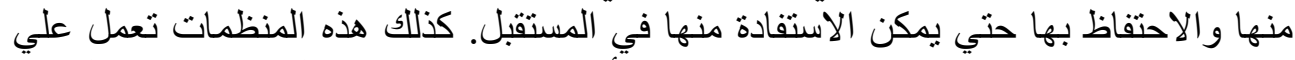

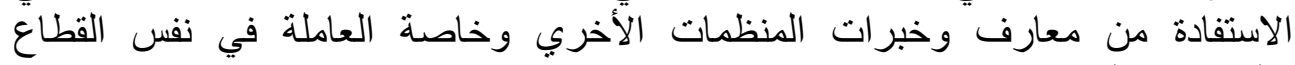
و والمنظمات المنافسة... و هنالك مكونات رئيسية تهتم بها منظمات التعلم هي كالتالي :

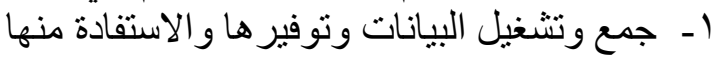

$$
\begin{aligned}
& \text { r - تشجيع البحث العلمي } \\
& \text { كـ ـ الاهتمام بالتدريب } \\
& \text { ع ـ ـ الاهتمام بالقر اعة بالترية } \\
& \text { 0ـ ـ الاهتمام بالمكتبة }
\end{aligned}
$$

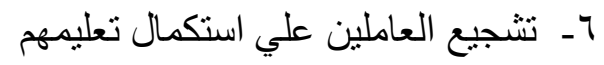

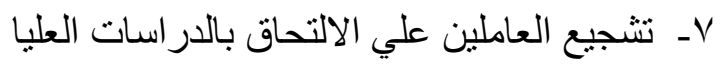

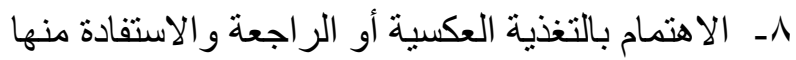

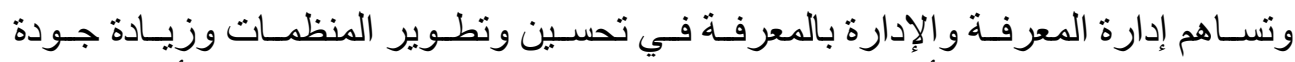

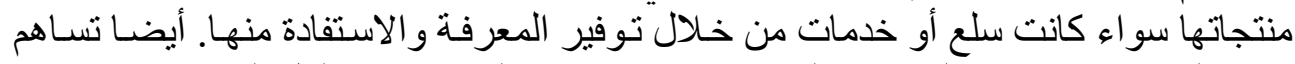

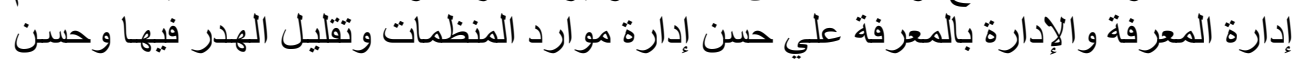




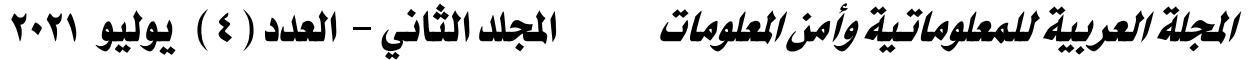

إدارة الوقت وسر عة انتاج السلع و أداء الخدمات( هنري جيلبرت Gilbert : 2013 ).

Henry

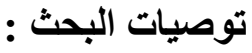

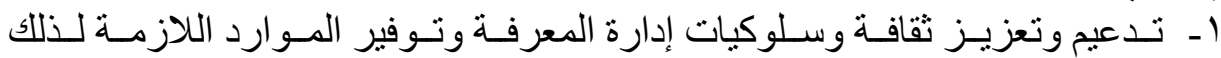

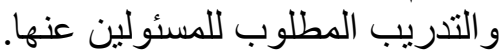

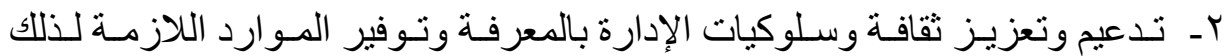

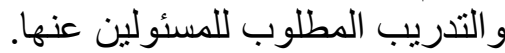

r- جعل التدريب مكون أساسي لنموذج الإدارة بالمعرفـة باعتباره يخلق قاعدة معرفية حديثة.

ع - إعطاء إدار ات المعلومـات و الحاسب الآلكي و التدريب حقهم من الاهتمـام التنظيمي

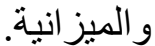

Oـ ـ تطبيق فكر الإدارة بالمكثوف أو الإدارة المفتوحة Open Book Management آ- ضرورة تشجيع العاملين لاستكمال تعليمهم والحصول علي درجات أعلي.

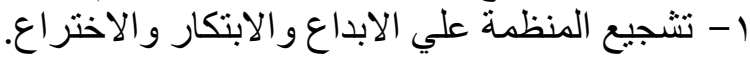

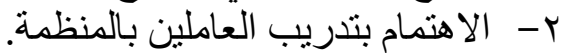

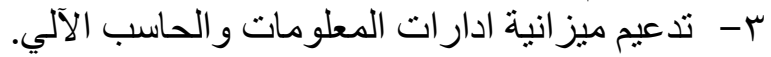

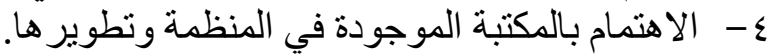

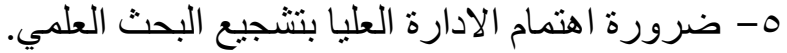

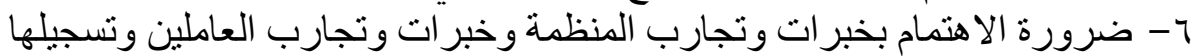
للاستفادة منها عندما يتم الحاجة إليها. 


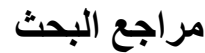 \\ أولاً : المراجع البحت العربية}

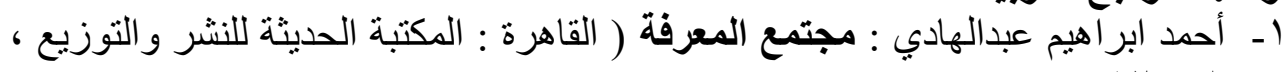

. ( r...

r- أحمد سيد مصطفي : التنظيم الإداري ( القاهرة : دار النهضة العربية للنشر و التوزيع ،

. ( $)$ ( ) 10

r- آلفين توفلر : صدمة المستقبل ، المتغيرات في عالم الغد ، ترجمة محمد علي ناصف

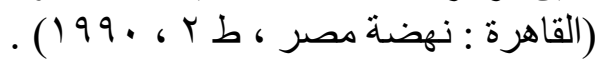

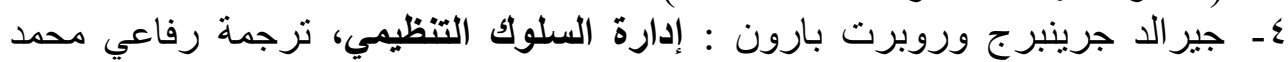

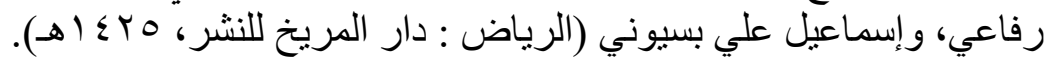

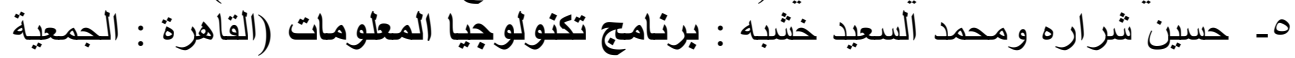

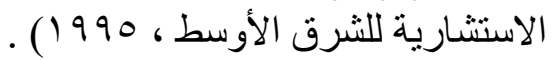

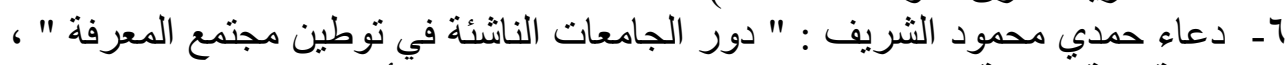

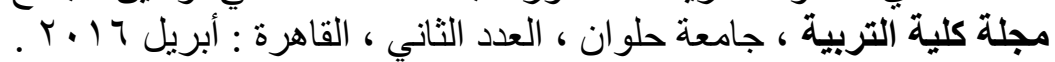

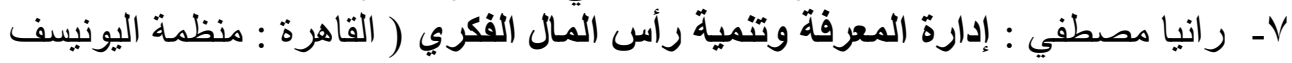
. ( r. ) ᄉ- سليمان الفارس : " دور إدارة المعرفة في رفع كفاءة أداء المنظمات ، دراسة ميدانية

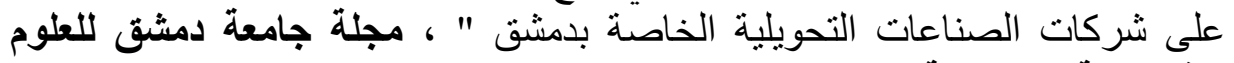

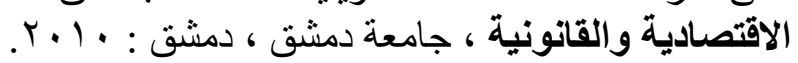

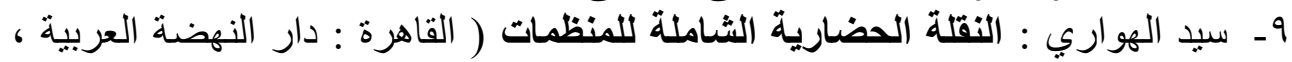
. ( r. ) • 1-سيد الهواري : الإدارة ، الأصول والأسس العلمية للقرن اץ ( القاهرة : مكتبة عين

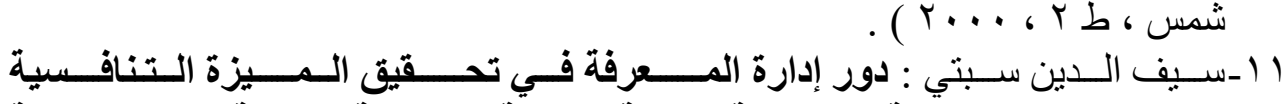

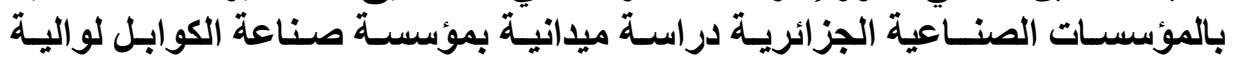

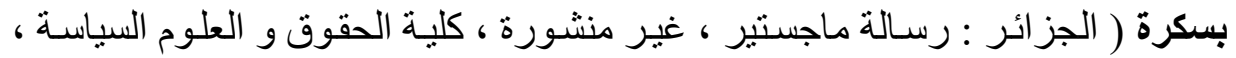

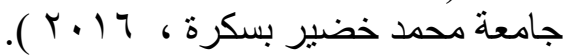

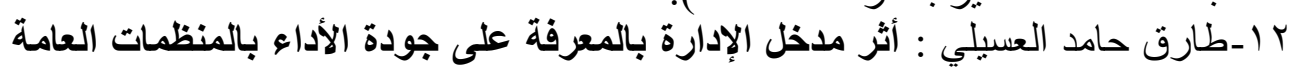

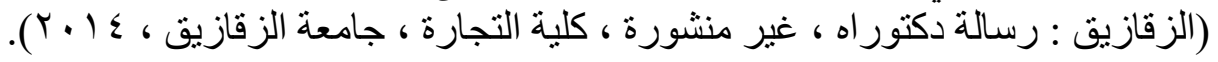

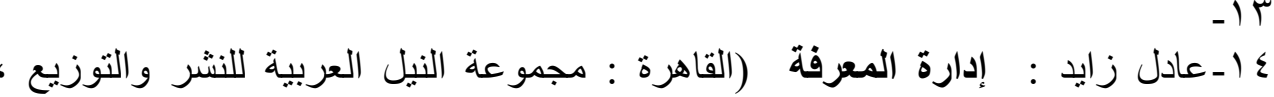
( $($ r. $) \varepsilon$ 


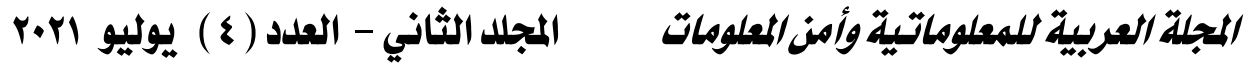

0 ـ ـ عبد الباسط محمد : مناهج البحث الاجتماعي ( القاهرة : المكتبة الحديثة للنشر و التوزيع . 7 ا ـعبد الرحمن العيسوي : مفاهيم البحث في علم النفس ( الاسكندرية : المكتب العربي

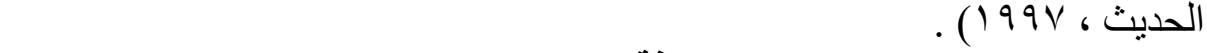
V V عبد الرحمن توفيق : الإدارة المعرفة (القاهرة: مركز الخبرات المهنية للإدارة، (Y...

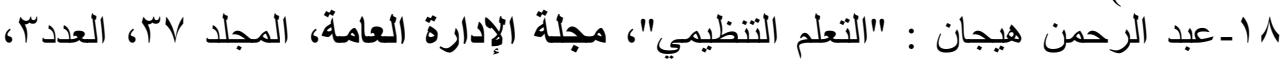
1991

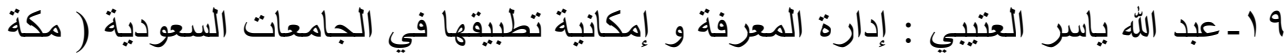

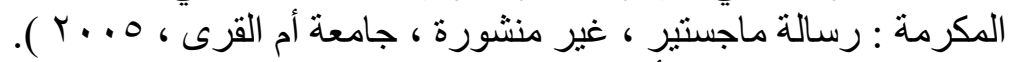

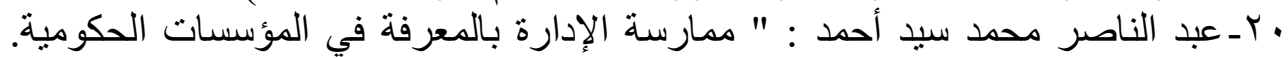

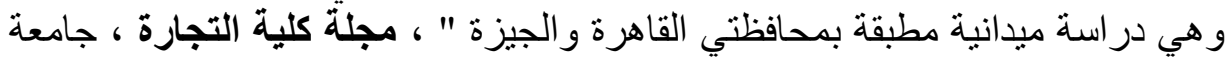

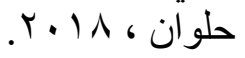

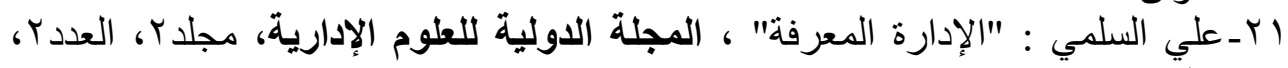

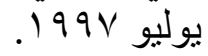

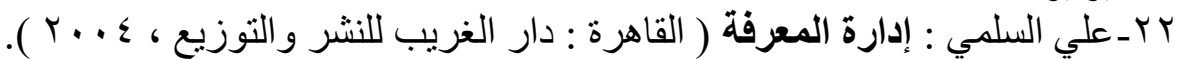

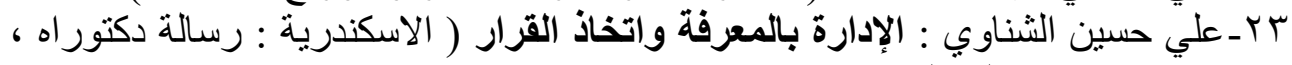

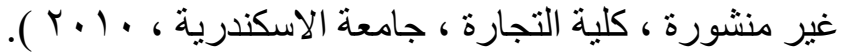

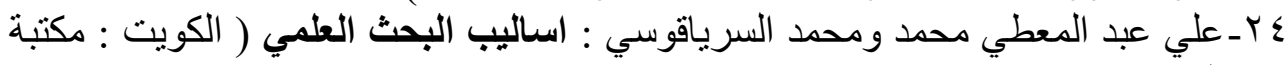

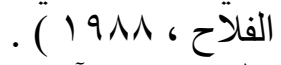

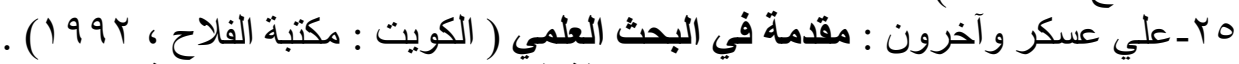

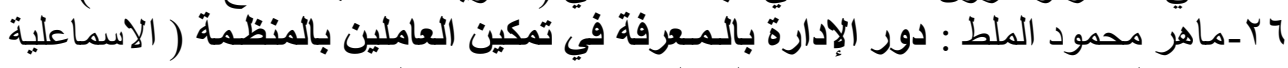

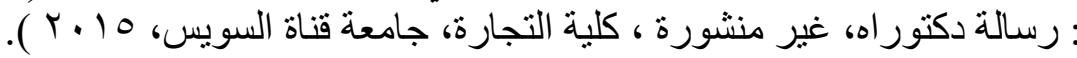

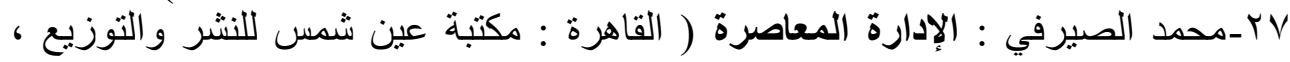
^ץ ـمحمد العيوطي : المعرفة ودورها في دعم اتخاذ القرار ( دبي : مركز دعم اتخاذ القرار

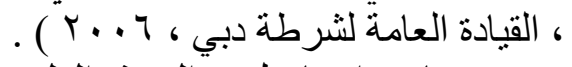

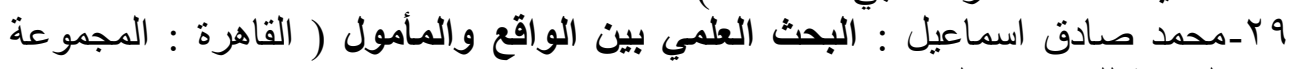

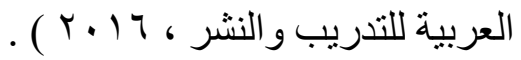
•r_محمد عاطف غيث وآخرون : قاموس علم اللم الاجتماع ( القاهرة : الهيئة المصرية العامة

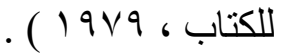


اس ـمحمد علي محمد : علم الاجتماع والمنهج العلمي ( الاسكندرية : دار المعرفة الجامعية

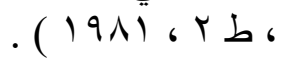

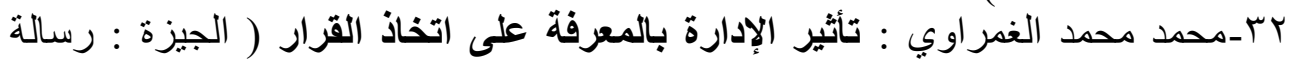

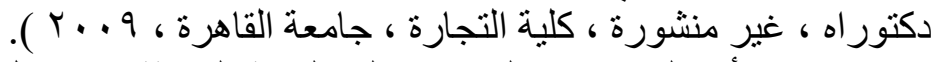

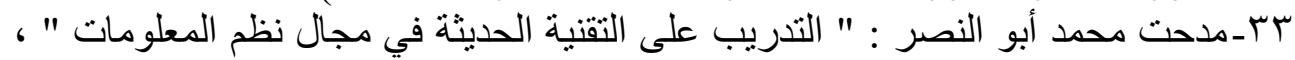

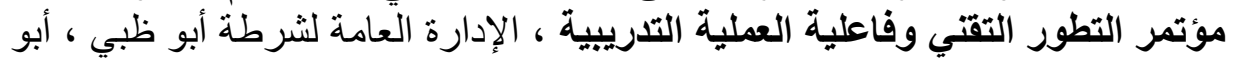

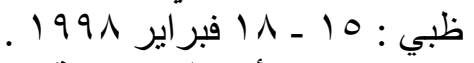

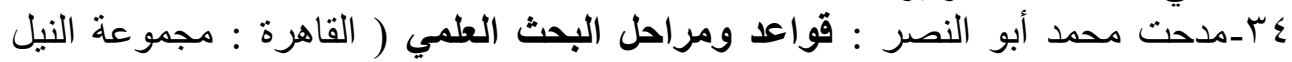

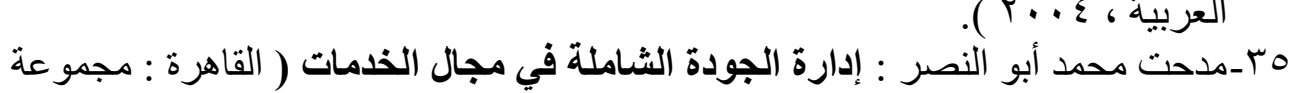

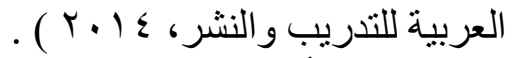

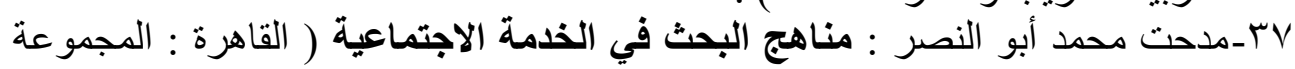

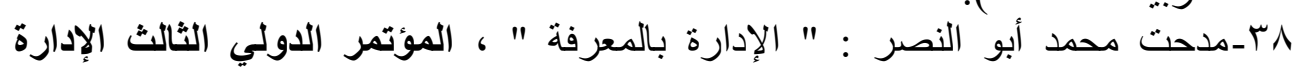

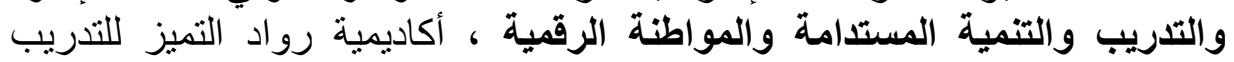

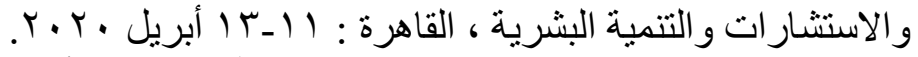

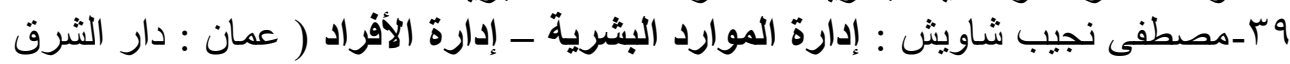

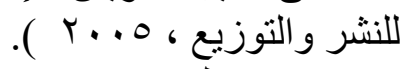
•عــمدوح عبد العزيز رفاعي : إدارة المعرفة ، مدخل رأس رأس المال الفكري ( القاهرة :

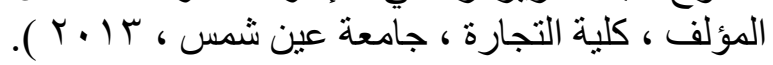

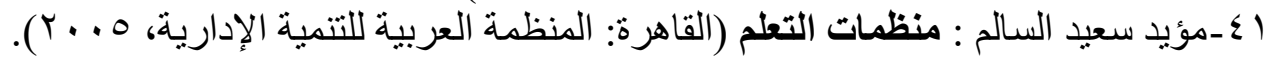

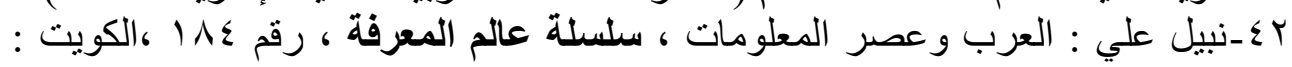

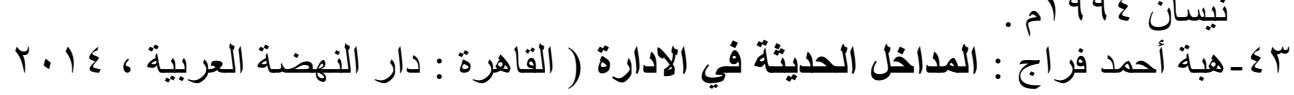
ثانيا : المراجع الأجنبية

1- A. Stylitz : Creation by Information and Knowledge ( N.Y.: 2010 ).

2- Allan Huga : Knowledge Management ( N.Y. : MC . Macmillan Company, 2010 ). 
3- D. Grey : “ knowledge Management and Competition in Consulting Industry “, Management Review,2005.

4- Ferry Waldo : " The role of the Upper management on the management by knowledge " , Business Management Review, Vol 3, June 2014.

5- Grey Denham : Knowledge Management and Information (N.Y. : Free Press , 2015 ) .

6- Henry Gilbert : Knowledge Society ( N.J. : McMillan Company , 2013.

7- Henry Ollan : The Impact of The management by knowledge and the decision making (Ohio : Ohio University, 2012).

8- Jo. Bryson : Effective Library \& Information Center Management (England: Gower Publishing, Co., 1990 ).

9- Joseph W. Wilkinson : Accounting and Information System (N.Y. : John Wiley \& Sons, Inc., 1991) .

10- Langenbach G. Robert : Introduction to Automated Data Processing ( N.Y.: Prentice- Hall, 1968).

11- M. Keri : Knowledge Management ( N.Y.: Prentice- Hall, 1997).

12- Matles Walsh : Information Management Systems ( Virginia :Reston Publishing Company, 1979) .

13- Merna Spenser : The Society Of 21 Century ( N.Y. : M c Millan Company, 2012 ).

14- Oxford English Dictionary ( Oxford : Oxford University Press , 2021).

15- Patrick G. Mckeown : Living With Computers ( N.Y. : H B J, 1991).

16- Peter Drucker : " The Discipline of Innovation " , Harvard Business Review , Nov.-Dec. 1998 .

17- Peter Senge : The Art ,Practice Of Learning Organization (N. Y. : Prentice - Hall Inc. 1990 ). 
18- R. Sanchez : Strategic Learning and Knowledge Management ( Wiley, Chichester, 1996 ).

19- Rachael Addicot : "Networks, Organizational Learning and Knowledge Management: NHS Cancer Networks". Public Money \& Management Journal, Vol. 26, No. 2, 2006.

20- Ralph M. Stair : Principles of Information System ( Boston : Boyd \& Fraser Publishing Company, 1992) .

21- Shelley Chasen \& Sylvia B. Cohen : Basic Computing ( N.Y.: Scholastic Inc.,1984).

22- Wikipedia Free Encyclopedia (2021) https://en.wikipedia.org/wiki/Main_Page

$$
\begin{aligned}
& \text { ثالثا : مواقع شبكة المعلومات الدولية ( الانترنت ) }
\end{aligned}
$$

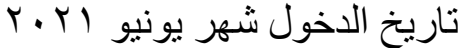

- https://mawdoo3.com/\%D8\%A8\%D8\%AD\%D8\%AB_\%D8

- https://ar.wikipedia.org/wiki/\%D8\%A5\%D8\%AF\%D8\%A7 